\title{
ErbB4 promotes malignant peripheral nerve sheath tumor pathogenesis via Ras-independent mechanisms
}

Jody Fromm Longo ${ }^{2 \dagger}$, Stephanie N. Brosius ${ }^{1,3+}$, Laurel Black ${ }^{2}$, Stuart H. Worley ${ }^{2}$, Robert C. Wilson ${ }^{2}$, Kevin A. Roth ${ }^{1,4}$ and Steven L. Carroll ${ }^{2^{*}}$ (i)

\begin{abstract}
Background: We have found that erbB receptor tyrosine kinases drive Ras hyperactivation and growth in NF1-null malignant peripheral nerve sheath tumors (MPNSTs). However, MPNSTs variably express multiple erbB receptors with distinct functional characteristics and it is not clear which of these receptors drive MPNST pathogenesis. Here, we test the hypothesis that altered erbB4 expression promotes MPNST pathogenesis by uniquely activating key cytoplasmic signaling cascades.
\end{abstract}

Methods: ErbB4 expression was assessed using immunohistochemistry, immunocytochemistry, immunoblotting and realtime PCR. To define erbB4 functions, we generated mice that develop MPNSTs with floxed Erbb4 alleles $\left(\mathrm{P}_{0}-\mathrm{GGF} \beta 3\right.$; Trp53 ${ }^{+/}$; Erbb4 $4^{\text {floxflox }}$ mice) and ablated Erbb4 in these tumors. MPNST cell proliferation and survival was assessed using ${ }^{3} \mathrm{H}$-thymidine incorporation, MTT assays, Real-Time Glo and cell count assays. Control and Erbb4-null MPNST cells were orthotopically xenografted in immunodeficient mice and the growth, proliferation (Ki67 labeling), apoptosis (TUNEL labeling) and angiogenesis of these grafts was analyzed. Antibody arrays querying cytoplasmic kinases were used to identify erbB4responsive kinases. Pharmacologic or genetic inhibition was used to identify erbB4-responsive kinases that drive proliferation.

Results: Aberrant erbB4 expression was evident in 25/30 surgically resected human MPNSTs and in MPNSTs from genetically engineered mouse models ( $\mathrm{P}_{0}-\mathrm{GGF} \beta 3$ and $\mathrm{P}_{0}-\mathrm{GGF} 33 ; \operatorname{Trp53} 3^{+/-}$mice); multiple erbB4 splice variants that differ in their ability to activate PI3 kinase and nuclear signaling were present in MPNST-derived cell lines. Erbb4-null MPNST cells demonstrated decreased proliferation and survival and altered morphology relative to non-ablated controls. Orthotopic allografts of Erbb4-null cells were significantly smaller than controls, with reduced proliferation, survival and vascularization. ERBB4 knockdown in human MPNST cells similarly inhibited DNA synthesis and viability. Although we have previously shown that broad-spectrum erbB inhibitors inhibit Ras activation, Erbb4 ablation did not affect Ras activation, suggesting that erbB4 drives neoplasia via non-Ras dependent pathways. An analysis of 43 candidate kinases identified multiple NRG1 $\beta$-responsive and erbB4-dependent signaling cascades including the PI3K, WNK1, STAT3, STAT5 and phospholipase-C $\gamma$ pathways. Although WNK1 inhibition did not alter proliferation, inhibition of STAT3, STAT5 and phospholipase-C $y$ markedly reduced proliferation.

Conclusions: ErbB4 promotes MPNST growth by activating key non-Ras dependent signaling cascades including the STAT3, STAT5 and phospholipase-CY pathways. ErbB4 and its effector pathways are thus potentially useful therapeutic targets in MPNSTs.

Keywords: Neurofibromatosis type 1, Schwann cell, erbB kinases, Cytoplasmic signaling pathways

\footnotetext{
* Correspondence: carrolst@musc.edu

${ }^{\dagger}$ Jody Fromm Longo and Stephanie N. Brosius contributed equally to this work.

2Department of Pathology and Laboratory Medicine (JFL, LB, RCW, SJW, SLC),

Medical University of South Carolina, 171 Ashley Avenue, MSC 908,

Charleston, SC 29425-9080, USA

Full list of author information is available at the end of the article
}

(c) The Author(s). 2019 Open Access This article is distributed under the terms of the Creative Commons Attribution 4.0 International License (http://creativecommons.org/licenses/by/4.0/), which permits unrestricted use, distribution, and reproduction in any medium, provided you give appropriate credit to the original author(s) and the source, provide a link to the Creative Commons license, and indicate if changes were made. The Creative Commons Public Domain Dedication waiver (http://creativecommons.org/publicdomain/zero/1.0/) applies to the data made available in this article, unless otherwise stated. 


\section{Background}

Malignant peripheral nerve sheath tumors (MPNSTs) are highly aggressive spindle cell neoplasms derived from the Schwann cell lineage [1]. These neoplasms are the most common malignancy occurring in patients with neurofibromatosis type 1 (NF1) [2]; they also occur sporadically in the general population and at sites of previous radiation therapy. There is an ongoing controversy as to whether NF1-associated, sporadic or radiation-induced MPNSTs have a worse prognosis [3-7]. However, it is generally agreed that in all of these clinical settings, MPNSTs have a poor prognosis, with several academic centers reporting 5-year disease-free survival rates of $34-60 \%[4,6-12]$. In large part, these poor outcomes reflect the fact that surgical resection is currently the only effective means of treating MPNSTs and achieving a complete surgical resection is often impossible. Developing effective new chemotherapeutic regimens is thus essential if we are to improve the survival of patients with these aggressive neoplasms.

Loss-of-function mutations of the NF1 tumor suppressor gene, which encodes the Ras inhibitor neurofibromin, are present in all NF1-associated MPNSTs and a major subset of sporadic and radiation-induced MPNSTs $[13,14]$. In the absence of neurofibromin, Ras activation is unopposed, resulting in Ras hyperactivation. Given this, it was reasonable to expect that agents targeting Ras or Ras-regulated cytoplasmic signaling cascades would be effective against MPNSTs. However, attempts to treat MPNSTs in this manner have thus far been unsuccessful. This reflects the fact that multiple Ras proteins are hyperactivated in MPNSTs [15] and that the key Ras-regulated signaling pathways in these tumors are poorly understood. This led us to hypothesize that an alternative approach, namely targeting the upstream proteins that drive Ras hyperactivation in NF1-null MPNSTs would be effective against MPNSTs. Prior to testing this hypothesis, though, we must identify the key Ras activating proteins in MPNSTs. Several lines of evidence suggest that one or more members of the erbB family of receptor tyrosine kinases (RTKs) fulfill this role in MPNSTs. We and others have shown that MPNSTs variably express erbB1 (the EGF receptor), erbB2, erbB3 and erbB4 [16]. These erbB kinases are constitutively activated in MPNST cells [16] and promote their proliferation [16] and migration [17]. Further, when we overexpressed an erbB3/erbB4-specific ligand [the neuregulin-1 (NRG1) isoform glial growth factor- $\beta 3$ (GGF 33 )] in the Schwann cells of transgenic mice ( $\mathrm{P}_{0}$-GGF $\beta 3$ mice), these animals developed neurofibromas [18] that transformed into MPNSTs in vivo $[18,19]$ with genomic abnormalities analogous to those seen in human MPNSTs [18]. Our subsequent genetic complementation experiments showed that NRG1 promotes MPNST pathogenesis by activating
erbB3 and erbB4-mediated signaling cascades that are dysregulated by neurofibromin loss [20].

These observations present a conundrum, thoughNRG1 activates both erbB3 and erbB4 and these receptors are often co-expressed in MPNSTs. Consequently, it is not clear which of them drives MPNST pathogenesis. This distinction has important mechanistic and therapeutic implications. NRG1 binds to erbB4 with an affinity an order of magnitude greater than that of erbB3 and, when activated, erbB4 has greater tyrosine kinase activity [21]. ErbB4 also responds to several ligands (NRG3, NRG4, betacellulin, epiregulin, heparin-binding EGF) that do not activate erbB3. As their intracellular domains contain distinct docking sites for cytoplasmic signaling molecules, the downstream signaling pathways activated by erbB4 differ from those regulated by erbB3 $[21,22]$. Further, erbB4, unlike other erbB kinases, can be proteolytically cleaved post-activation $[23,24]$, releasing a cytoplasmic fragment that functions as a transcriptional regulator [25]. It is thus likely that if erbB4 promotes MPNST pathogenesis, it does so via mechanisms different from erbB3. If erbB4 promotes MPNST pathogenesis, it would also represent a potential target for new therapeutic agents such as the monoclonal antierbB4 antibodies that are currently in development. Consequently, here we test the hypothesis that erbB4 promotes MPNST pathogenesis and that it does so by activating cytoplasmic signaling cascades distinct from those regulated by erbB3.

\section{Methods}

\section{Reagents and antibodies}

A mouse anti-GAPDH monoclonal antibody (clone 6C5) was purchased from Fitzgerald Antibodies and Antigens (Concord, MA). Rabbit anti-erbB4 antibodies were from Santa Cruz (sc-284) and Abcam (ab35374; Cambridge, MA). Rabbit anti-actinin (\# 6487) and anti-S100 $\beta$ antibodies were purchased from Cell Signaling and Dako (Carpinteria, CA), respectively. Nestin (clone rat-401), pan-Ras (clone Ras-10), and erbB4 (HFR1; \#05-1133) mouse monoclonal antibodies were from Millipore (Billerica, MA). Anti-Ki67 and anti-CD31 antibodies were obtained from Abcam (ab15580 and ab23364). Actin Green-488 ready probe, and Alexa Fluor 568 were purchased from Invitrogen; Cy3-, fluorescein isothiocyanate (FITC)- and horseradish peroxidase-conjugated secondary antibodies were from Jackson Immunoresearch (West Grove, PA). IRDye 680RD and IRDye800CW secondary antibodies were from LI-COR (Lincoln, NE). Cy3 Tyramide Signal Amplification kits were from Perkin Elmer (Waltham, MA), while Immpress Polymer Detection Reagents were purchased from Vector Laboratories (Burlingame, CA). The PLCY inhibitor U73122 (\#11264868-7) was from Selleckchem. Stat5 (CAS 285986-31-4; 
\#573108) and Stat3 (5, 15-DPP; \#D4071) inhibitors were from Sigma.

\section{Human MPNST specimens and lines}

Paraffin blocks of surgically resected human MPNSTs were from the files of the UAB Department of Pathology. We have previously described the sources of our human MPNST cell lines [16, 17, 26, 27]. MPNST cells were maintained in Dulbecco's modification of Eagle's medium (DMEM) supplemented with $10 \%$ fetal calf serum, $10 \mu \mathrm{g} / \mathrm{mL}$ streptomycin and 10 $\mathrm{IU} / \mathrm{mL}$ penicillin (DMEM10). Cell line identities were validated by short tandem repeat analyses as recommended by ATCC Technical Bulletin 8. The morphology and doubling times of these cultures were monitored and cells were tested at regular intervals by PCR for Mycoplasma.

\section{Immunoblotting and immunohistochemistry}

Cells were lysed and immunoblotted using our previously described methodology [20]. Immunoreactive species were identified using enhanced chemiluminescence (Pierce) or Licor IRDye secondaries. We have found that detection of erbB4 is highly dependent on lysis conditions; for details and a comparison of erbB4 detection under different lysis conditions, see Additional file 1: Figure S1. Activated Ras was pulled down using the Raf1-Ras binding domain (ThermoFisher; Waltham, MA) and detected with a pan-Ras antibody as previously described [20]. Nestin, S100ß, and Ki67 immunohistochemistry, TUNEL labeling and determination of Ki67 and TUNEL labeling indices was performed per our previously described methodologies [20]. To quantify vascular densities, 3-4 independent images of CD31immunostained sections from each graft (Cre-ablated and control) of UBI-1 and UBI-2 cells were analyzed with ImageJ using the "automated counting of singlecolor image" function.

\section{RNA interference}

A pool of four siRNAs targeting erbB4 (L-003128-00-005) and a non-targeting control pool (D-001810-10-05) were purchased from Thermo Scientific (Waltham, MA), while WNK1 (Sigma TRCN0000000919, TRCN0000219718) and erbB4 shRNAs (TRCN00000001410, TRCN00000001411) were obtained from the Hollings Cancer Center shRNA Shared Resource. Cells plated in DMEM-10 (200,000 cells/ well in 6 well plates) were transfected with siRNAs using X-TREME Gene siRNA transfection reagent (Roche, Indianapolis, IN; 5:2 transfection reagent:siRNA). Cells were transduced with shRNAs using our previously described methodology [15].

\section{Quantitative PCR (qPCR)}

1000 ng of total RNA isolated using Trizol (Life Technologies) was converted to cDNA using a SuperScript Vilo RT Kit (Invitrogen). 5-20 ng of cDNA was used for qPCR with TaqMan primer sets following the manufacturers' protocol. The TaqMan primer sets used were: pan-erbB4: Hs00171783_m1 (spans exons 12-13, detects all isoforms), Hs00955522_m1 (spans exons 26-27; CYT1 specific), Hs00955509_m1 (spans exons 14-15; JMb specific), Hs00955511_m1 (spans exons 16-17; JMa specific), a custom set for CYT2 (spans exons 25-27; 5' primer: 5'-CAACATCCC ACCTCCCATCTATAC-3', 3' primer: 5'ACACTCC TTGTTCAGCAGCAAA-3', probe a: 5'AATTGACTC GAATAGGAACCAGTTTGTATACCGAGAT-3') and GAPDH (Hs99999905_m1, Mm99999915_g1).

\section{In vitro proliferation and survival assays}

Tritiated thymidine incorporation assays were performed as previously described [26] with cells plated at a density of 20,000 cells per well in 48 well plates. For Real-Time Glo and MTT assays, 4,000 or 20,000 log phase cells per well were plated in 96 or 48 well plates, respectively, and assays performed following the manufacturers' instructions. For total cell count proliferation assays the Celigo Imaging Cytometer was used in conjunction with DAPI nuclear total cell stain and propidium iodine staining. Cells were imaged every other day for five to 7 days.

\section{Genetically engineered mouse models}

Mice were maintained according to the NIH Guide for the Care and Use of Laboratory Animals (Eighth Edition). Standard cages were used to house mice, with food and water available ad libitum.

We have previously described the generation and characterization of $\mathrm{P}_{0}-\mathrm{GGF} \beta 3 ; \operatorname{Trp} 53^{+/-}$mice [20]. $E_{r b b 4}{ }^{-1-} ; \alpha-M H C-E r b b 4$ mice [28] were provided by Dr. Andres Buonanno. Mice with exon 2 of the Erbb4 gene

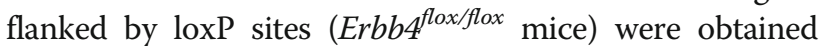
from Dr. Kent Lloyd [29]. $\mathrm{P}_{0}$-GGF $33 ; \operatorname{Trp} 3^{+/-}$mice were mated to Erbb $4^{\text {floxfflox }}$ mice and the resulting progeny then mated to each other to generate $\mathrm{P}_{0}$-GGF $33 ; \operatorname{Tr} p 53^{+/}$; $E r b b 4^{f l o x / f l o x}$ mice. Offspring were screened via PCR using previously described primers for the $\mathrm{P}_{0}$-GGF $\beta 3$ transgene, Trp53 null alleles [19, 20], Erbb4 $4^{\text {flox }}$ and Erbb4 wild-type alleles [30].

\section{Diagnosis of mouse tumors}

Mice were examined daily for our previously described indicators of tumor development [20]; complete necropsies were performed on mice with suspected tumors and early passage cultures prepared from tumors per our previously established methods $[18,20]$. Tumor diagnoses were 
performed following World Health Organization (WHO) diagnostic criteria as we previously described [20].

\section{Erbb4 ablation with adenoviral vectors}

Mouse MPNST cells were plated $(100,000$ cells $/ \mathrm{mL})$ in DMEM10. The next morning, cultures were rinsed with PBS and infected with Ad5CMVCre-eGFP or Ad5-eGFP (Gene Transfer Vector Core, University of Iowa; Iowa City, IA) in $10 \mathrm{~mL}$ DMEM (MOI 100) for $8 \mathrm{~h} ; 10 \mathrm{~mL}$ DMEM10 was then added. $24-48 \mathrm{~h}$ post-transfection, GFP-positive cells were sorted on a BD Biosciences FACS Aria machine using FACS Diva software (Franklin Lakes, NH). Erbb4 deletion was assessed using previously described primers [31] which generate a 250 base pair band from recombined ErbB $4^{\text {flox }}$ alleles and a 350 base pair band from non-recombined alleles.

\section{Orthotopic allografts}

$48 \mathrm{~h}$ after transduction with Ad5CMVCre-eGFP or Ad5eGFP and FACS sorting, 50,000 GFP-positive MPNST cells were orthotopically allografted into the sciatic nerves of Hsd: Athymic Nude-Foxn $1^{\text {nu }}$ mice (Harlan Laboratories; Indianapolis, IN) per our previously published protocol [32].

\section{Antibody arrays}

The phosphorylation of 43 kinases and two related proteins was assessed using Proteome Profiler PhosphoKinase Arrays (\#ARY003B; R\&D Systems, Minneapolis, MN). MPNST cells were serum starved overnight and then stimulated with $10 \mathrm{nM}$ NRG1 $\beta$ for $5 \mathrm{~min}$. Cells were lysed and arrays processed and developed per the manufacturer's recommendations. Signals were quantified using the Protein Array Analyzer Plug In for FIJI.

\section{Differentially expressed genes and RNA sequencing}

Total RNA was isolated using standard Trizol based methods from FACS-sorted UBI1, 2, and 3 cells approximately 2 days after infection with Ad5CMVCre-eGFP or Ad5-eGFP. RNA integrity was verified on an Agilent 2200 TapeStation (Agilent Technologies, Palo Alto, CA); samples with RINs $\geq 8$ were used for sequencing. RNASeq libraries were prepared from total RNA (100-200 ng) using the TruSeq RNA Sample Prep Kit per the manufacturer's protocol (Illumina, San Diego, CA). Libraries were clustered at a concentration that ensured at least 50 million reads per sample on the cBot as described by the manufacturer (Illumina, San Diego, CA). Clustered RNA-seq libraries were then sequenced using Version 4 with 1 X50 cycles on an Illumina HiSeq2500. Demultiplexing was performed utilizing bcl2fastq-1.8.4 to generate Fastq files. RNA from three biological replicates was sequenced. Sequencing reads (single end reads, 50 million depth) were aligned using the DNAStar software. Partek and DNAStar were used to identify statistically significant expression changes of at least 1.5fold up or down compared to controls. The analysis for this paper was generated using Partek $^{\bullet}$ software (Ver 7.0; Partek Inc., St. Louis, MO, USA). Gene ontology analysis of statistically significant genes affected by erbB4 loss were analyzed with a ranked gene list using Panther's over-represented analysis tools.

\section{Results}

Aberrant expression of erbB4 is evident in MPNSTs

Our previous analyses of two MPNST cell lines and six tumor samples indicated that erbB4 was variably expressed in these neoplasms [16]. To determine how commonly erbB4 is expressed in MPNSTs in vivo and examine its distribution in these tumors, we immunostained thirty surgically resected human MPNSTs (see Additional file 1: Table S1 for the demographics and NF1 status of these patients). Twenty-five tumors (83\%) were positive for erbB4 and demonstrated prominent membranous (Fig. 1a, erbB4 stain; b, control nonimmune IgG stain) and/or nuclear (Fig. 1c) immunoreactivity. The membranous staining was often punctate, consistent with our previous observations in MPNST cells [17]; this is also consistent with the fact that erbB4 functions as a microenvironment sensor at the plasma membrane but can also get proteolytically cleaved and enter the nucleus to function as a transcriptional coactivator. Intratumoral variability was evident, with both erbB4-positive and -negative tumor cells present in the same neoplasm. Upon scoring the number of erbB4 positive tumor cells in each MPNST, we found that in most $(16 / 25)$ tumors, the majority [ $>75 \%(4+$; Fig. $1 \mathrm{~d})$ or $50-75 \%$ (3+; Fig. 1e)] of the tumor cells were erbB4 immunoreactive. In another seven tumors, erbB4 staining was less widely distributed, with $25-50 \%$ of the tumor cells being erbB4 positive (2+; Fig. 1f). The remaining two erbB4-positive MPNSTs contained < 10-25\% erbB4-immunoreactive cells (data not shown).

To compare erbB4 expression in MPNST cells to that in non-neoplastic human Schwann cells, we performed real time PCR quantification of ERBB4 mRNA levels in 16 MPNST cell lines (Fig. 1g), with MCF7 cells serving as a positive high expressing control. Eleven lines had ERBB4 expression greater than that in Schwann cells, with the highest levels observed in MPNST642, NMS2, NMS2-PC and T265-2c cells, and intermediate expression levels in 2XSB, sNF02.2, S462, 90-8TL, MPNST2, sNF96.2, and sNF94.3 cells. Four lines (ST88-14, STS26 T, HS-PSS, Hs-Sch2) had ERBB4 expression that was slightly lower than Schwann cells. A comparison of erbB4 protein and mRNA expression in a selected subset of MPNST lines showed that all of the lines that expressed ERBB4 mRNA also had detectable erbB4 

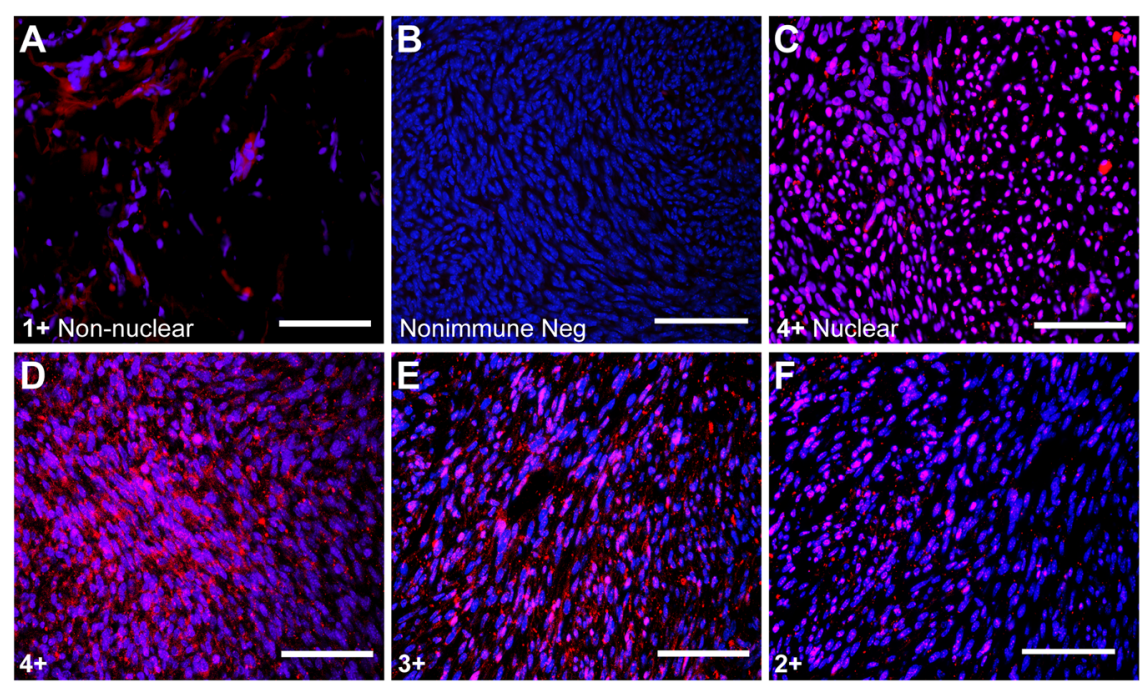

G

H
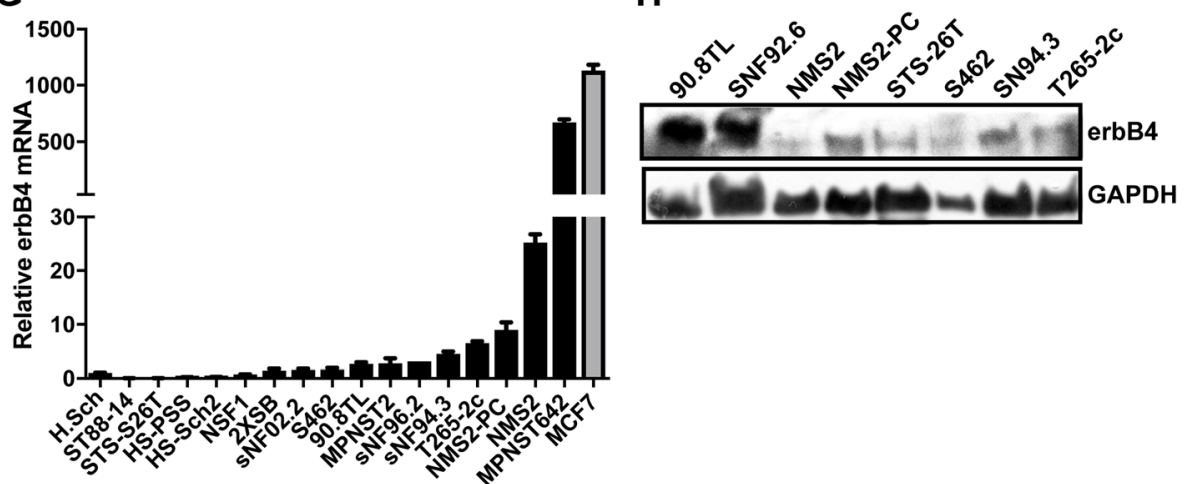

Fig. 1 ErbB4 is commonly expressed in human MPNSTs and MPNST-derived cell lines. a-f Representative images of erbB4 immunostaining of FFPE sections of human MPNSTs demonstrates different grades of erbB4 staining compared to isotype matched negative control $\mathbf{b}$. The erbB4 grading is represented numerically on a scale between 1+ to 4+. A subset of erbB4 positive tumor samples displayed prominent nuclear staining (c-f) and others displayed exclusive non-nuclear membranous staining (a). Red channel (Alexa 568, erbB4). Blue channel (Hoechst, nuclei). Scale bar represents 100um. $\mathbf{g}$ Real time PCR analysis showing relative mRNA expression of erbB4 mRNA using non-isoform discriminatory PCR primers; mRNA levels are shown relative to human Schwann cells. GAPDH mRNA was used as the loading control for normalization. $\mathbf{h}$ ErbB4 protein expression of by immunoblot analysis of whole cell lysates derived from human MPNST derived cell lines. GAPDH was used as a loading control

protein (Fig. 1h). However, ERBB4 mRNA levels were not necessarily predictive of erbB4 protein levels, suggesting that post-translational factors regulate erbB4 protein levels in MPNST cells.

Alternative splicing of ERBB4 mRNAs results in the production of functionally distinct protein variants that contain different juxtamembrane domains (JMa, JMb variants) and either include or lack a sequence in the autophosphorylation domain of the receptor (CYT1 and CYT2 variants, respectively). JMa variants, unlike JMb isoforms, can undergo proteolytic cleavage to release a $120 \mathrm{kDa}$ fragment that acts as a transcriptional regulator. The CYT1 sequence contains a p85 docking site that allows erbB4-mediated activation of the PI3 kinase/Akt signaling cascade. To determine which ERBB4 splice variants are predominantly expressed in MPNST cells, we performed real-time PCR with isoform specific primer/probe sets (Additional file 1: Figure S2A). We found that most MPNST cell lines had higher expression of JMa than JMb variants while CYT1 and CYT2 variant expression was comparable across our panel of cell lines (Additional file 1: Figure S2B and C).

\section{ErbB4 promotes proliferation, survival and angiogenesis in MPNSTs}

To determine whether erbB4 promotes the proliferation and survival of human MPNST cells, we targeted ERBB4 expression using shRNAs in cell lines (S462, T265-2c, and MPNST642) with increased erbB4 mRNA and protein expression compared to Schwann cells and assessed total cell number over a 5-day period of growth (Fig. 2a and b). Decreased erbB4 expression was confirmed by 
western blot; in these cells, we found that proliferation was also inhibited by loss of erbB4 expression. These findings were further supported by both MTT and ${ }^{3} \mathrm{H}-$ thymidine incorporation assays in MPNST cells transiently transfected with pooled siRNA ERBB4 or nonsense control siRNAs; ERBB4 knockdown in these cultures showed smaller numbers of viable cells relative to cultures receiving nonsense control siRNAs (Additional file 1: Figure S3A-C), a change due, at least in part, to decreased proliferation.

Our previously described $\mathrm{P}_{0}$-GGF $33 ; \operatorname{Trp} 53^{+/-}$genetically engineered mouse (GEM) model develops MPNSTs de novo with complete penetrance [20]; like human MPNSTs, these GEM tumors and early passage cultures derived from them express erbB4 (Fig. 2c; Additional file 1: Figure S2D). We therefore decided to use this model to further dissect erbB4's role in MPNST pathogenesis in vivo. Unfortunately, however, we could not generate $\mathrm{P}_{0}$-GGF $\beta 3 ; \operatorname{Trp}_{53}{ }^{+/-}$mice with germline Erbb4 deletion as germline Erbb4 loss produces cardiac defects that result in embryonic lethality [33]. The approach of introducing floxed Erbb4 alleles into MPNSTs and deleting them with $\mathrm{CreER}^{\mathrm{T} 2}$ was also problematic as our initial experiments indicated that mosaicism would complicate the interpretation of these experiments. We therefore tried crossing $\mathrm{P}_{0^{-}}$GGF $33 ; \operatorname{Trp} 53^{+/-}$mice to mice in which $E_{b b} 4^{-/-}$lethality is rescued by re-expressing erbB4 in the heart (Erbb4 ${ }^{-1-} ; \alpha-\mathrm{MHC}-E \mathrm{rbb} 4$ mice). However, out of 65 pups expected to have the desired $\mathrm{P}_{0}$-GGF 33 ; $\operatorname{Trp} 53^{+/-} ;$Erbb $^{-/-} ; \alpha-\mathrm{MHC}-$ Erbb4 genotype, we obtained only one pup with this genotype and it did not produce any progeny.

We thus took the alternative approach of producing $\mathrm{P}_{0}$-GGF $33 ; \operatorname{Trp} 53^{+/-} ; E r b b 4^{\text {flox } f l o x}$ mice, with the goal of deleting Erbb4 ex vivo, grafting the cells back into mice and then assessing the effects of Erbb4 ablation on tumor growth. The survival of $\mathrm{P}_{0}$-GGF $33 ; \operatorname{Trp} 53^{+/-}$; Erbb4floxflox mice (average survival, 210 days; Fig. 2d) was indistinguishable from that of $\mathrm{P}_{0}$-GGF $33 ; \operatorname{Trp} 53^{+/-}$ mice [20]. Peripheral nervous system tumors were present in nearly $100 \%$ of the $\mathrm{P}_{0}$-GGF $33 ; \operatorname{Trp} 53^{+/-}$;Erbb $4^{\text {flox/flox }}$ mice; these tumors were most commonly associated with trigeminal nerves, with some evident in sciatic nerve or dorsal root ganglia (Additional file 1: Table S2). The tumors in $\mathrm{P}_{0}$-GGF 33 ;Trp $53^{+/-}$;Erbb4 $4^{\text {flox flox }}$ mice were markedly hypercellular MPNSTs with brisk mitotic activity (Fig. 2e) and immunoreactivity for $S 100 \beta$ and nestin (Fig. 2f-h). As tumor penetrance and lifespan in $\mathrm{P}_{0}$-GGF 33 ;rp $53^{+/}$; Erbb4 $4^{\text {flox/flox }}$ mice and $\mathrm{P}_{0}$-GGF $\beta 3$; Trp53 ${ }^{+/-}$; mice was similar, we concluded that the floxed Erbb4 alleles did not impede tumorigenesis or worsen the survival of these mice.

To determine what effects erbB4 loss had in these tumors, we established early passage $\mathrm{P}_{0}$-GGF $\beta 3 ; \operatorname{Tr} p 53^{+/-}$;
Erbb $4^{f l o x / f l o x}$ MPNST cultures and transduced them with adenovirus expressing eGFP or eGFP-Cre recombinase. eGFP-positive cells were isolated via FACS from each treatment group. PCR analyses verified the presence of recombined Erbb4 alleles and Erbb4 mRNA reductions (Additional file 1: Figure S3D and E) in the presence of Cre recombinase, but not in controls. Erbb4 ablation did not reduce the expression of Egfr, Erbb2 or Erbb3 mRNAs (Additional file 1: Figure S3F) indicating that the changes described below are unlikely to reflect indirect effects on the expression of other erbB family members. The purified tumor cells were viable but demonstrated morphologic changes. In contrast to the spindled morphology of cells with intact Erbb4 alleles (Fig. 2i), the Erbb4 knockout cells were ameboid with shorter, thicker processes and often showed nuclear blebbing (Fig. 2i. GFP vs Cre). To determine whether Erbb4 ablation in $\mathrm{P}_{0}$-GGF $33 ; \operatorname{Trp} 53^{+/-} ;$Erbb $^{\text {floxfflox }}$ MPNSTs inhibited viability, we performed MTT assays on transduced cultures of three independently arising MPNSTs. We found that cultures transduced with Creexpressing adenovirus showed decreased numbers of viable cells compared to cells infected with the control vector (Fig. 2j). As in human MPNST cells, ${ }^{3} \mathrm{H}$-thymidine incorporation assays demonstrated that this decrease in cell numbers was due, in part, to reduced proliferation (Fig. 2k).

To examine the effects of Erbb4 ablation in vivo, the three distinct $\mathrm{P}_{0^{-}}$GGF $33 ; \operatorname{Trp} 53^{+/-}$;Erbb4 $4^{\text {flox/flox }}$ early passage MPNST cultures previously assessed by MTT and ${ }^{3} \mathrm{H}$-thymidine incorporation assays (Fig. 2j-k) were transduced with eGFP- or eGFP-Cre expressing adenovirus, FACs sorted and then orthotopically allografted in the sciatic nerves of nude mice. The grafts were excised 35 days post-grafting, and their masses and volumes determined. Grafts of Erbb4-ablated tumor cells showed overall reduction in volume and mass relative to grafts of cells transduced with eGFP-expressing adenovirus (Fig. 3a and b). The cellularity of the Erbb4-null tumors was lower than that of the eGFP controls (Fig. 3c, Ctl vs Cre) and the Erbb4 knockout cells had more prominently vacuolated cytoplasm. The expression of erbB4 in the resultant tumors was assessed in several excised tumors from each UBI cohort. Expression of erbB4 was found to be lower in Cre erbB4 ablated tumors versus $\mathrm{Ctl}$ erbB4 expressing tumors (Fig. 3d, Ctl vs Cre). The degree of erbB4 expression was slightly variable between data sets but is supportive in the trend observed with tumor mass/volume data. Our immunohistochemical data thus supports the hypothesis that the larger tumors we observed in our Cre-mediated knockout cohorts likely resulted from the presence of erbB4 expressing cells that escaped Cre-mediated gene ablation rather than a lack of dependence on erbB4. 

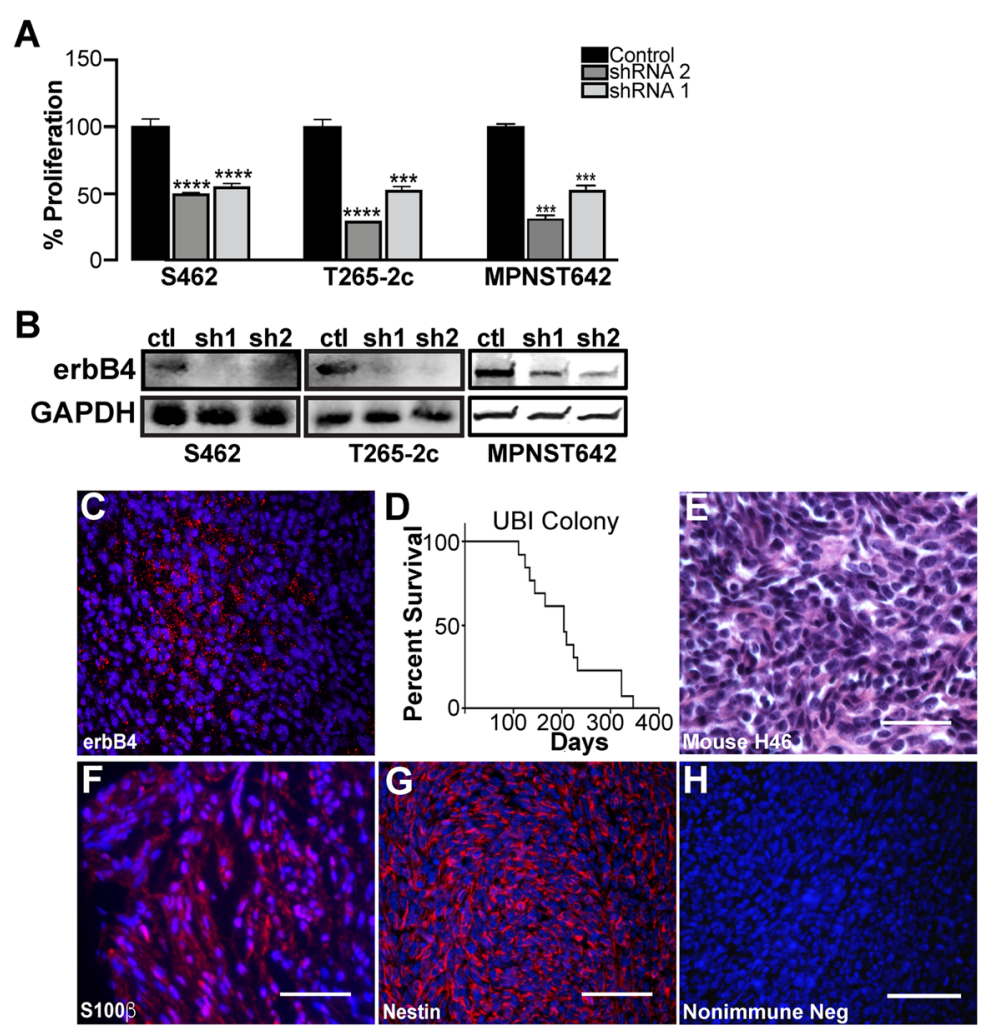

I
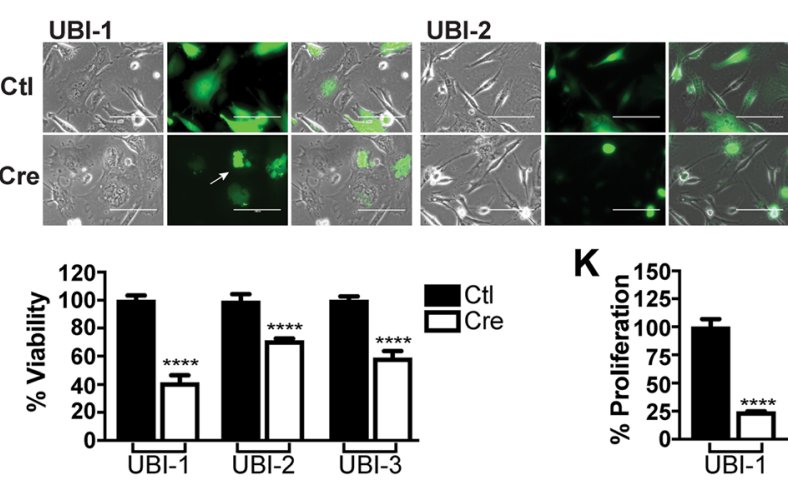

UBI-3
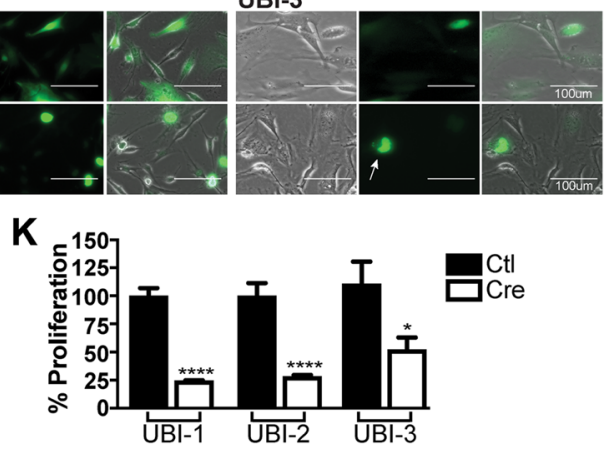

Fig. 2 Loss of ErbB4 in human and mouse MPNST cells inhibits proliferation and survival. a Compared to non-targeting controls, erbB4 knockdown in cells had a decrease in cellular proliferation. b Immunoblots demonstrating reduced erbB4 expression in low erbB4 expressing cells (T265-2c, S462) and high expressing cells (MPNST642) cells infected with erbB4 shRNAs relative to cells infected with a non-targeting control. **, $p$-value $\leq 0.01 ;{ }^{* * *}, p$-value $\leq 0.001 ;{ }^{* * * *}, p$-value $\leq 0.0001$. c Representative erbB4 immunostaining of $\mathrm{P}_{0}-\mathrm{GGF} \beta 3 ;$ Trp53 ${ }^{+/-}$;Erbb4 $4^{\text {flox/flox }} \mathrm{GEM}$ mouse tumors showing erbB4 positivity compared to isotype matched negative controls $\mathbf{( h )}$. These representative erbB4 immunostains also show punctate membranous staining, with immunoreactivity present in almost all tumor cells (4+ staining). d) Kaplan-Meier survival curve of ${ }^{\text {/llox }}$ mice shows that these animals survive an average of 210 days, similar to the parent line $\mathrm{P}_{0}$-GGF $\beta 3 ; T r p 53^{+-}$mice. e) Like their parent line, $\mathrm{P}_{0^{-}}$

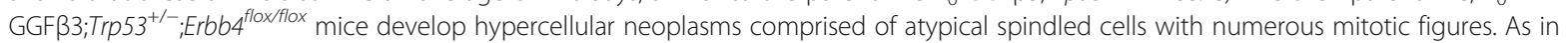
human MPNSTs, these tumors are also immunoreactive for both $\mathrm{S100 \beta}(\mathbf{f})$ and nestin $(\mathbf{g})$. $\mathbf{h}$ Isotype-matched negative control for erbB4 staining of mouse tumors. i Representative infection efficiency of UBI MPNST cell lines. MPNSTs with intact Erbb4 alleles (control, non-recombined) have a spindled morphology similar to that of wild-type Schwann cells, whereas knockout cells (Cre) are more ameboid. Nuclear blebbing was evident in a subset of Erbb4-ablated tumor cells (arrow). Images were imaged at 40X on Brightfield and GFP channels. Infected cells are represented on the green channel due to GFP target sequence in the adenovirus. j, $\mathbf{k}$ Decreased cellular viability (j) and proliferation (k) was observed in the Erbb4 knockout cells (Cre) compared to the control cells from three independent tumor cultures. ${ }^{*}, p$-value $\leq 0.05$; ${ }^{* * *} p$-value $\leq 0.0001$ for comparisons of recombined (Erbb4 -) with non-recombined (Erb64+) alleles. Red channel (Alexa 565, erbB4). Blue channel (Hoechst, nuclei)

To determine whether this decrease in graft mass and volume reflected decreased tumor cell proliferation or survival, we quantified the Ki67 and TUNEL labeling indices in five Erbb4-ablated and five control grafts established from each of the three early-passage cultures. In all instances, there were statistically significant 


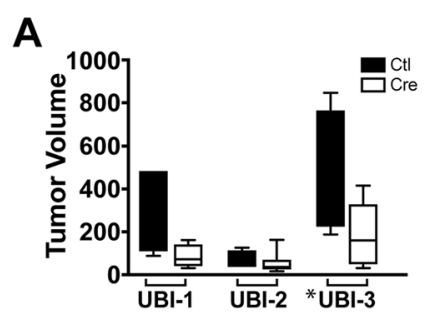

B
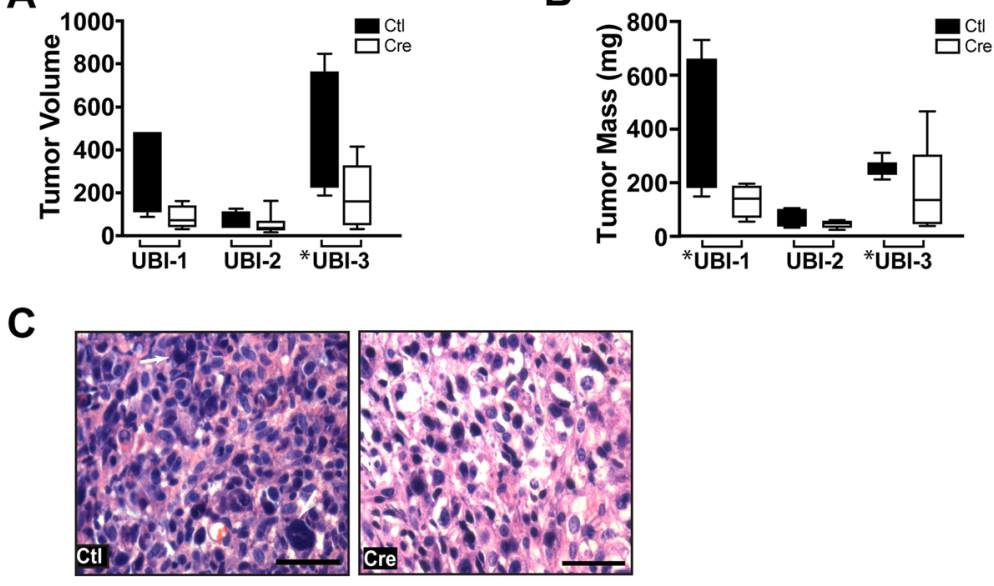

D

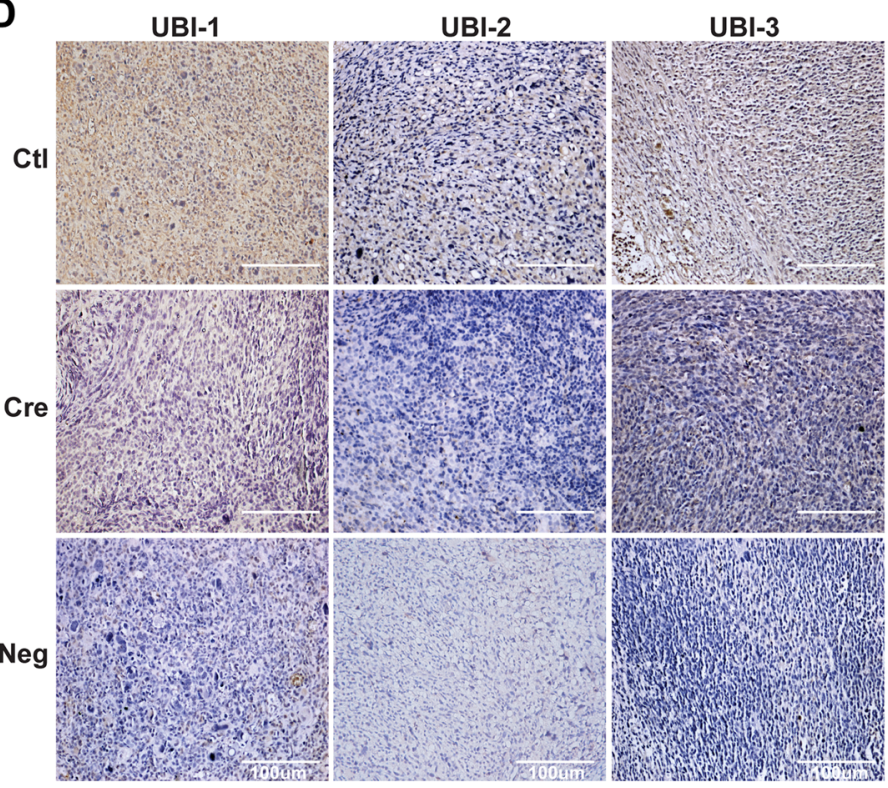

Fig. 3 Erbb4 ablation inhibits allograft growth and alters tumor histopathology in Nude mice. $\mathbf{a}$ and $\mathbf{b}$ ) Erbb4-null cells from three separate tumor lines show reduced graft volume (a) and mass (b) compared to erbB4 expressing controls. $p$-values $\leq 0.05$ are designated with an asterisk $(*)$, Tumor mass p-values are as follows: UBI-1: 0.049, UBI-2: 0.069, and UBI-3: 0.005; F-Test. c Representative histologic images of a UBI GFP control tumor and a UBI Cre tumor taken at 40X. Arrows in CtI indicate the multinucleated cells that are commonly seen in these tumors. Note that these multinucleated cells are virtually absent in the Erbb4-null grafts. $\mathbf{d}$ Representative chromogenic erbB4 stained images of UBI GFP control tumor and UBI Cre tumors displaying decreased erbB4 expression in Cre ablated xenografts compared to control tumors taken at 20X

decreases in Ki67 labeling in the Erbb4-null grafts relative to eGFP controls (Fig. 4a). In addition, the Erbb4-ablated allografts demonstrated a 3-4-fold increase in the percentage of TUNEL positive cells relative to the control grafts (Fig. 4b). Erbb4 loss thus results in both decreased proliferation and increased apoptosis in these grafts.

During our gross examination of the grafts, we noted that the Erbb4 ablated grafts were paler than the controls, raising the question of whether vascular density was decreased in the grafts lacking Erbb4. Upon immunostaining our grafts for the vascular marker CD31, we found that the vascular density in the Erbb4 ablated grafts (Fig. 4g-i) was lower than that in the control allografts [(Fig. 4c-e; a nonimmune control primary antibody was used as a negative control (Fig. 4f)]. Quantification of the vascular densities in these grafts showed that the vascular density in the Erbb4 ablated grafts was approximately half that of the control grafts (Fig. 4j). As Erbb4 is intact in the vasculature within these grafts, this suggests that the decreases in vascular density observed in Erbb4 ablated grafts are an indirect effect of Erbb4 loss in MPNST cells via mechanisms such as erbB4-mediated enhancement of the production and/or secretion of angiogenic factors by MPNST cells. 


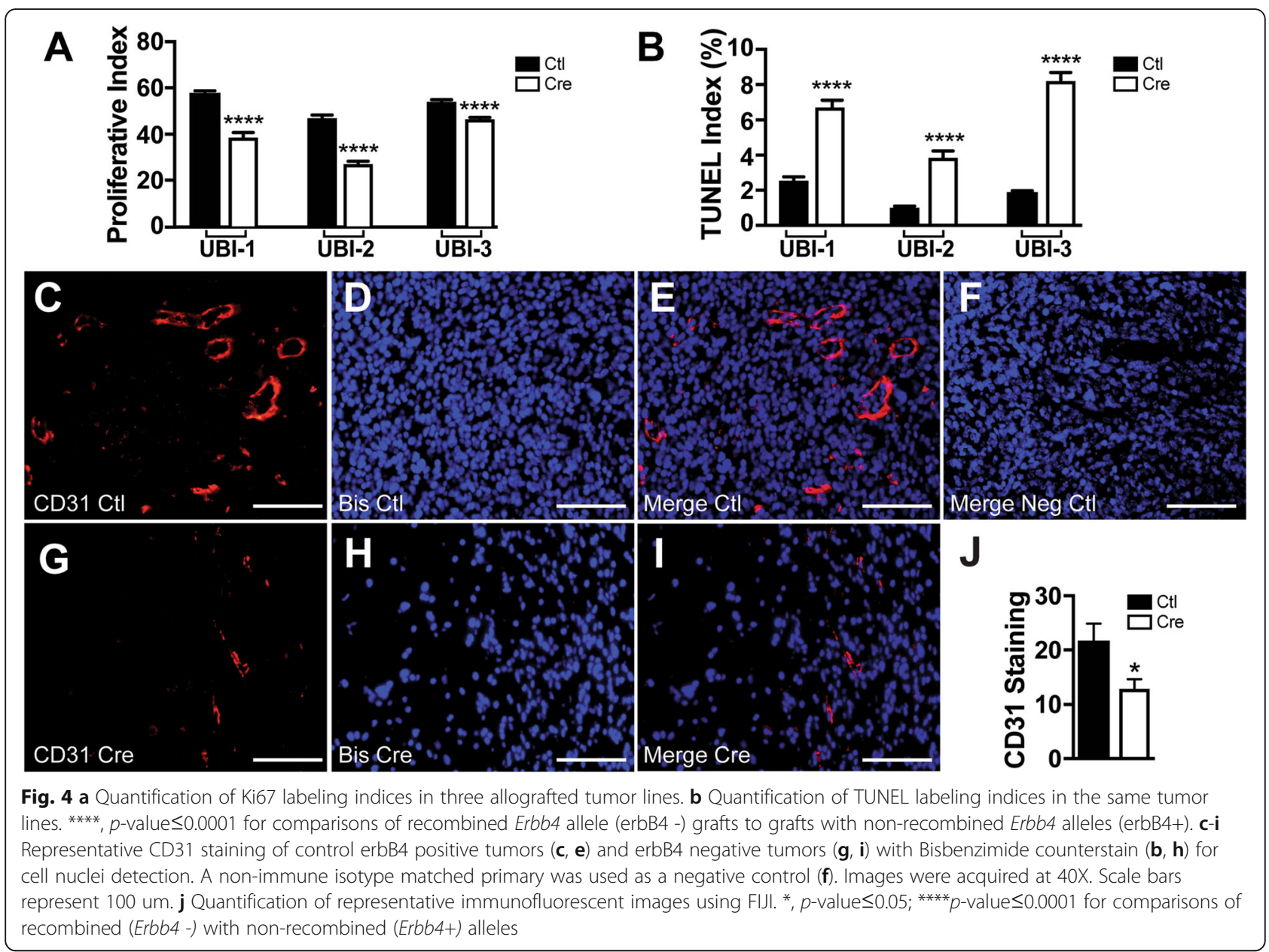

ErbB4 mediates basal and NRG1-stimulated phosphorylation of multiple cytoplasmic kinases, but is not essential for Ras hyperactivation

Although MPNSTs co-express erbB3 and erbB4, our demonstration that Erbb4 ablation decreased proliferation, survival and angiogenesis in MPNSTs indicates that these receptors are not functionally redundant and suggest that erbB4 activates distinct signaling cascades essential for MPNST tumorigenesis. As many growth factors, including NRG1 [34], activate Ras, we first asked whether Erbb4 ablation diminished the erbB-dependent Ras hyperactivation we have previously observed in $\mathrm{P}_{0^{-}}$ GGF $33 ; \operatorname{Trp} 53^{+/-}$MPNSTs [20]. To answer this question, we generated lysates from early passage $\mathrm{P}_{0}$-GGF 33 ; $\operatorname{Trp} 53^{+/-} ; E$ Erbb $4^{\text {flox } f l o x}$ MPNST cells transduced with eGFP or eGFP-Cre expressing adenovirus, pulled down the activated Ras proteins with Raf- 1 and then probed the captured Ras proteins using a pan-Ras antibody (Fig. 5a). Surprisingly, we found that Ras activation was not reduced by Erbb4 ablation, indicating that Erbb4 loss impairs MPNST proliferation and survival via effects on Rasindependent pathways. Immunocytochemistry confirmed reduced erbB4 expression in adeno-Cre-GFP infected cells compared to adeno-Cre-GFP infected cells (Fig. 5b), indicating that continued Ras activation did not reflect a failure of erbB4 ablation.

As a further assessment of the biological functions impacted by Erbb4 loss, we performed RNA-Seq on UBI-1, 2 , and 3 cell lines transduced with GFP- or Cre/GFP-expressing adenovirus, identified the genes whose expression was significantly changed $\geq 1.5$-fold and performed gene ontology analyses on these genes. Using Panther overrepresented analysis tools [35] to identify the top pathways (Fig. 6a) and molecular function activities (Fig. 6b) affected by Erbb4 loss, we identified angiogenesis, adhesion, proliferation and cation signaling as key erbB4-regulated functions. These findings were thus consistent with the in vitro and in vivo observations described above.

To further explore the erbB4 mediated signaling driving proliferation, survival and angiogenesis in MPNSTs, we stimulated Erbb4 intact and Erbb4-null GGFB3; $\operatorname{Trp} 53^{+/} ;$Erbb $4^{\text {flox/flox }}$ MPNST cells with $10 \mathrm{nM}$ NRG1 $\beta$ for $5 \mathrm{~min}$, a time that our preliminary analyses indicated was sufficient to maximally activate NRG1 $\beta$-responsive 


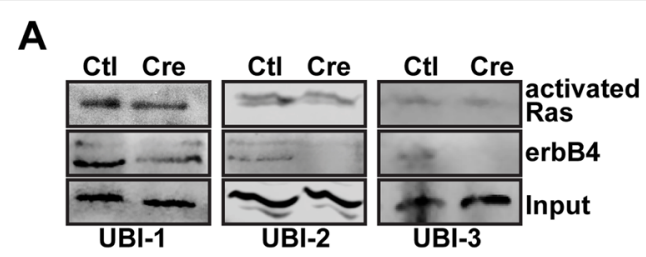

B

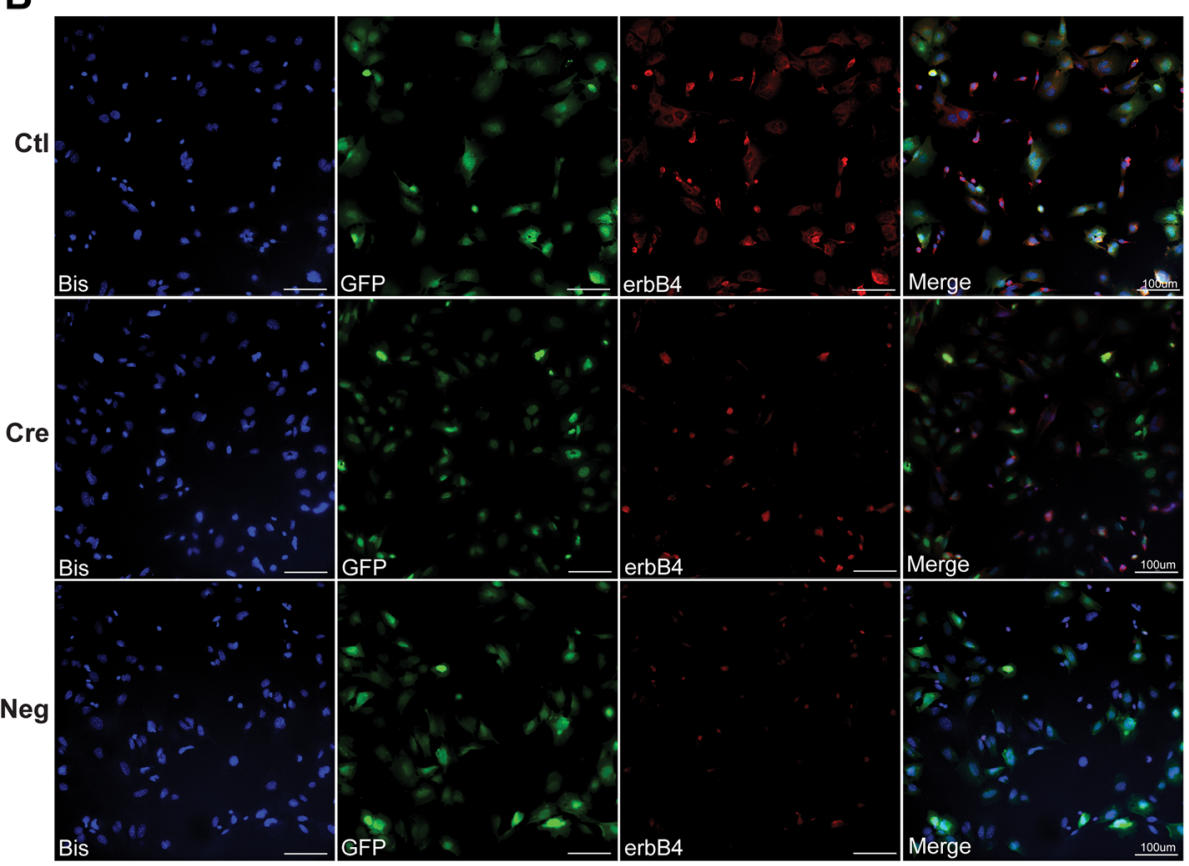

Fig. 5 Erbb4 is not essential for Ras hyperactivation. a A comparison of Ras activation in Erbb4-null (Cre) and Erbb4-expressing control (Ctl) UBI 13 MPNST cells shows that Erbb4 loss does not affect Ras activation. b Immunocytochemistry staining of Erbb4-null (Cre) and Erbb4-expressing control (CtI) UBI MPNSTs cells displays reduced erbB4 expression in adeno-viral infected cells (GFP positive). Representative erbB4 staining of control erbB4 positive tumors (Ctl) and erbB4 negative tumors (Cre) with Bisbenzimide counterstain for cell nuclei detection. A non-immune isotype matched primary was used as a negative control. Images were acquired at 20X. Scale bars represent 100 um

signaling pathways. Lysates from these cells were used to probe arrays containing phosphorylation site-specific antibodies that query 43 different cytoplasmic kinases and other key proteins (Additional file 1: Figure S4). We then asked which of these proteins showed altered phosphorylation following NRG1 $\beta$ stimulation and Erbb4 ablation.

We first identified the NRG1 $\beta$ responsive proteins and

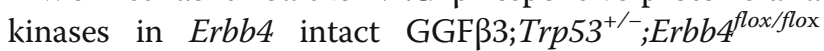
MPNST cells; as NRG1 $\beta$ activates both erbB3 and erbB4, alterations in the phosphorylation of the proteins queried by our arrays in these cells could reflect the action of either erbB3 or erbB4. Kinases whose phosphorylation levels were changed by at least 1.5 -fold compared to unstimulated cells were considered NRG1 $\beta$ responsive. Using this criterion, we identified 13 NRG1 $\beta$ responsive sites with increased phosphorylation and 4 NRG1 $\beta$ responsive events in which the phosphorylation of the targeted protein was decreased (Fig. 7a). The proteins in which NRG1 $\beta$ increased phosphorylation included Akt (T308), RSK, PRAS40 [also known as AKT1S1 (Akt1 substrate 1)], Src, Hck, Fyn, STAT3 (S727 and Y705), PYK2, PLC 1, p53 (S46) and Chk-2; of particular note, given that we have previously shown that Ras is activated in $\mathrm{P}_{0^{-}}$GGF $33 ; \operatorname{Trp}_{53}{ }^{+/-}$MPNSTs by NRG1 [20], we found that the phosphorylation of ERK was also increased by NRG1 $\beta$ stimulation in these experiments. In contrast, the phosphorylation of S473 in pAKT (unlike T308, another activation site in Akt, where phosphorylation was increased by NRG1ß; see above), JNK, STAT5a/b (Y694/Y699) and $\beta$-catenin was decreased following NRG1 $\beta$ stimulation. However, since decreased phosphorylation of $\beta$-catenin results in increased transcriptional activity, this latter change reflects increased activation of the $\beta$-catenin pathway downstream of NRG1ß.

To determine which phosphorylation events noted above required NRG1 $\beta$-mediated activation of erbB4, we compared the stimulated phosphorylation profile of Erbb4 intact cells to that of Erbb4 ablated cells (Fig. 7b). We found that two of the 18 NRG1 $\beta$-responsive 


\section{A}

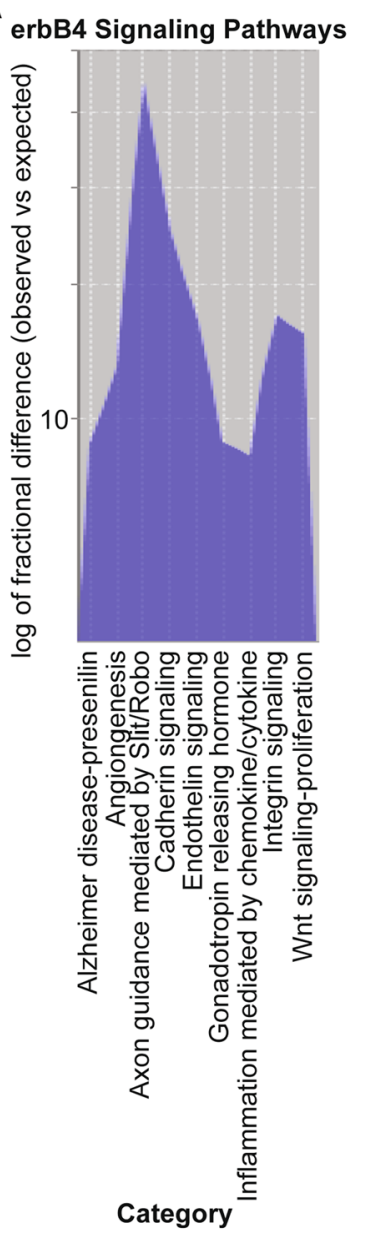

B

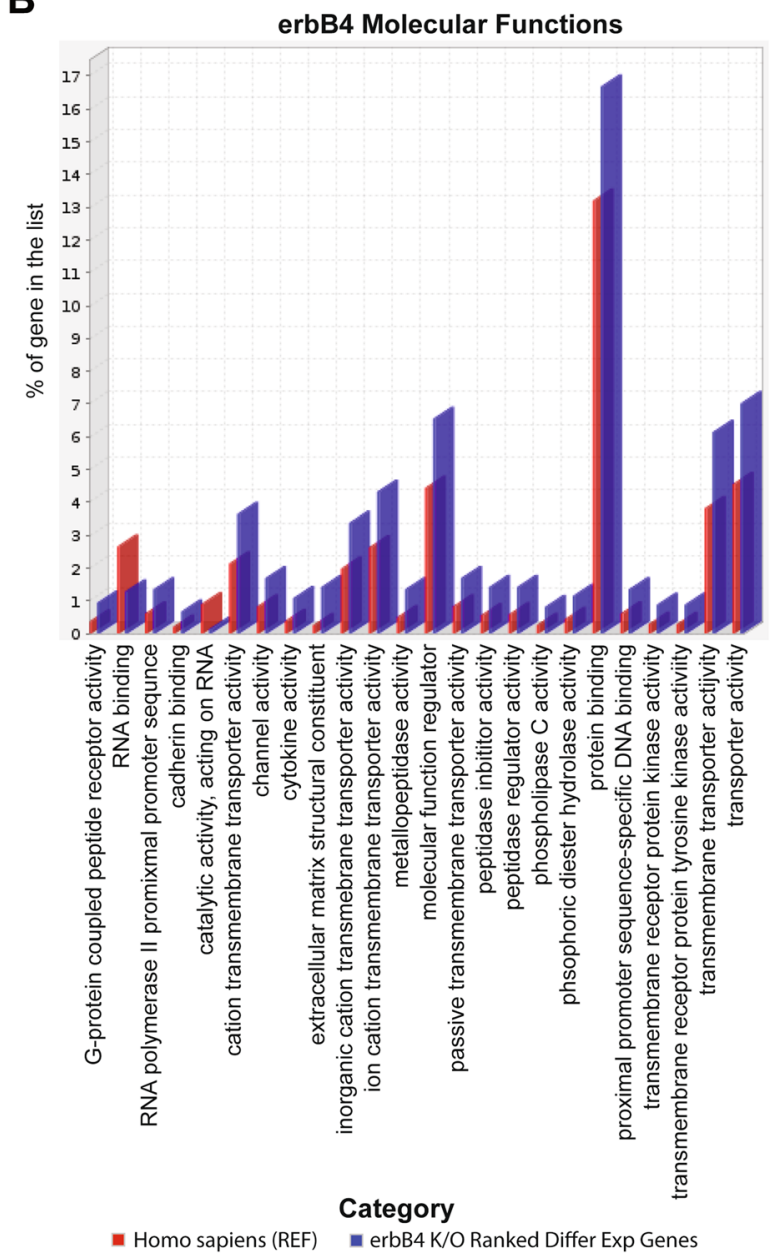

Fig. 6 RNA-Seq pathway analysis of differentially affected genes in erbB4 knockout UBI MPNST cells. Partek analysis of NextGen RNA sequencing identified differentially expressed genes. Genes with a fold change of at least 1.5 up or down were put through Panther gene over representation enrichment analysis to identify erbB4 affected signaling pathways (a) and molecular function activity (b). Graphs represent the ratio of overrepresented genes differentially affected by erbB4 loss compared to expected reference representation. This analysis highlights the role of erbB4 in migration, angiogenesis and PLCY signaling

phosphorylation events were partially dependent on the presence of Erbb4 (PRAS40, Akt-T308) suggesting that erbB3 and erbB4 redundantly regulate these PI3K pathway proteins downstream of NRG1 $\beta$ through distinct heterodimers. The phosphorylation of six kinases (Src, Hck, Chk-2, p53-S46, STAT5a and b) was completely dependent on NRG1 $\beta$ and intact Erbb4, indicating that NRG1 $\beta$-driven phosphorylation of these targets is mediated, directly or indirectly, by erbB4. Interestingly, several of the changes we observed suggested that erbB3 and erbB4 play opposing roles in activating some signaling pathways in MPNSTs. For instance, the phosphorylation of STAT5a/b at Y694/699, two sites that are required for activation, was weakly (0.66 fold down) decreased by NRG1 $\beta$ in the presence of Erbb4. However, in the absence of Erbb4, NRG1 $\beta$ stimulation resulted in an almost complete loss of STAT5a/b activation, suggesting that erbB4 opposes erbB3-mediated inhibition of STAT5a/b. The reduction in pAkt-S473 phosphorylation observed in response to NRG1 $\beta$ stimulation (Fig. 7a) was also rescued by Erbb4 ablation, with pAktS473 returning to baseline levels in the presence of NRG1 $\beta$ (Fig. 7b). In contrast, the reduction in $\beta$ catenin phosphorylation levels observed in response to NRG1 $\beta$ stimulation was further exaggerated when Erbb4 was ablated, suggesting both erbB3 and erbB4 activate this signaling cascade. The remaining six NRG1 $\beta$-responsive proteins (RSK, Fyn, STAT3-Y705/ S727, PLC $\gamma-1$, PYK2) had phosphorylation that was enhanced by erbB4, both in the presence and absence of exogenous NRG1 $\beta$ (Fig. 7b). This latter observation may reflect erbB4 activation mediated by endogenous NRG1 $\beta$ expressed by the tumor cells themselves or, alternatively, the action of other erbB4 ligands 


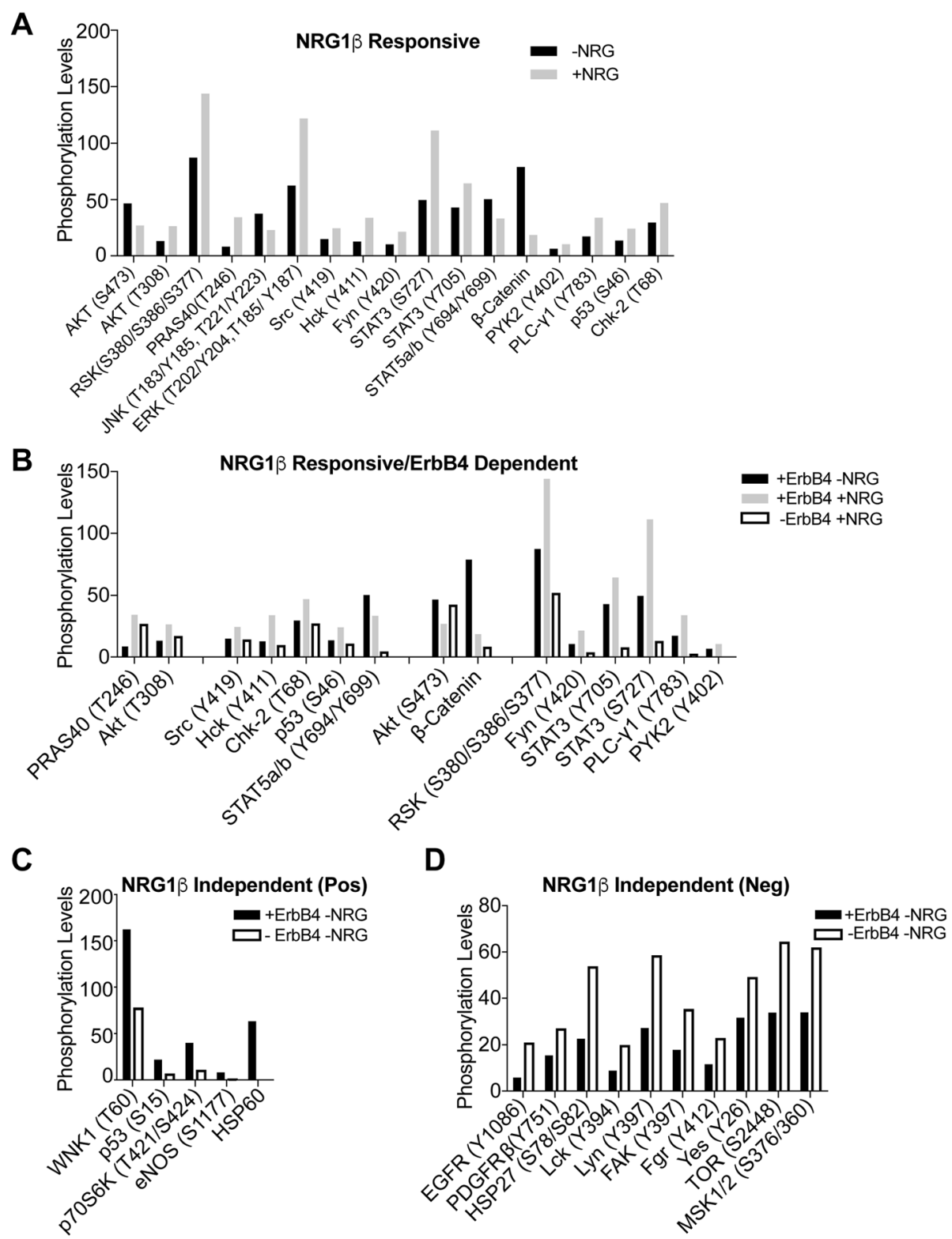

Fig. 7 Erbb4 increases the phosphorylation of a number of other cytoplasmic kinases, independent of Ras activation. a Graphical representation of quantified kinase arrays comparing the levels of baseline phosphorylation to NRG1 stimulated phosphorylation in Erbb4-expressing UBI MPNST cells. The graph includes the subset of kinases whose phosphorylation was altered following NRG1 $\beta$ stimulation. $\mathbf{b}$ Graphical representation of quantified kinase arrays comparing the levels of baseline phosphorylation of control Erbb4-intact cells to NRG1 stimulated ErbB4-intact and Erb64null UBI MPNST cells to determine NRG1 dependent and ErbB4 dependent kinases. c) Quantification of a subset of the non-responsive kinases ErbB4-intact compared to ErbB4-ablated to identify targets positively regulated by ErbB4 independent of stimulation. d) Quantification of a subset of the non-responsive kinases ErbB4-intact compared to ErbB4-ablated to identify compensatory targets resulting from ErbB4-ablation independent of stimulation. Quantification of the kinases differentially phosphorylated was quantified per the manufacturer's protocol using ImageJ

expressed by the MPNST cells that similarly activate downstream signaling cascades.

We next asked whether there were additional proteins whose phosphorylation was dependent upon Erbb4 but unaffected by NRG1 $\beta$ stimulation. We identified 15 proteins whose phosphorylation was not altered when challenged with exogenous NRG1 $\beta$ but that were sensitive to
Erbb4 ablation. Erbb4 ablation decreased the phosphorylation of five of these proteins [WNK1, p53 (S15), p70S6K, eNOS, and HSP60; Fig. 7c), suggesting that Erbb4 is a key upstream activator of these kinases. Erbb4 loss increased the phosphorylation of the other ten proteins in a NRG1 $\beta$ independent manner suggesting that erbB4 negatively regulates the activation of these proteins. This latter group of 
proteins included two RTKs, EGFR and PDGFR $\beta$, as well as HSP27, five Src-related kinases (Lck, Lyn, FAK, Fgr, Yes), mTOR and MSK1/2 kinases (Fig. 7d). The majority of these proteins are associated with the plasma membrane and their activation in the absence of erbB4 may be a direct result of altered receptor heterodimerization and cellular architecture at the plasma membrane.

\section{MPNSTs are sensitive to inhibitors targeting erbB4 activated signaling pathways}

To directly assess whether the proteins whose phosphorylation is altered by Erbb4 loss include molecules that promote MPNST proliferation and/or survival, we inhibited the actions of four of these proteins (WNK1, PLCy, STAT3 and STAT5a). Although our shRNAs effectively knocked down WNK1 expression in T265-2c and S462 cells, MTT assays did not show a reproducible decrease in the number of viable cells following knockdown (Additional file 1: Figure S5A). In contrast, the PLC $\gamma$ inhibitor U73122 inhibited the viability of T265-2c, S462 and MPNST642 cells (Fig. 8a). Likewise, the STAT3 inhibitor Cas285986-31-4 also inhibited the viability of three MPNST cell lines in a concentration-dependent manner (Fig. 8b). The STAT5 inhibitor 5,15-DPP also decreased the number of viable cells in cultures of these lines, although its effects were not as pronounced as those of the STAT3 inhibitor (Fig. 8c). To further confirm these observations, at least two to three gene specific shRNAs against PLC $\gamma$, STAT3 and STAT5 were employed in a proliferation assay over a five-day growth period to challenge these drug studies. Knockdown of PLC $\gamma$, STAT3, and STAT5 resulted in a decrease in total cell number in a cell-type dependent manner (Fig. 9a). S462 and T265-2c were sensitive to decreased PLCy expression and displayed a decrease in total cell number. ST88-14 cells had a less pronounced effect on cell number, likely due to poor PLCY knockdown efficiency. STAT3 and STAT5 shRNA mediated knockdown both downregulated MPNST total cell number in all three cell lines in protein expression dependent manner (Fig. 9b and c). We conclude that PLC $\gamma$, STAT3 and STAT5 are among the key erbB4 regulated targets to mediate the proliferation and/or survival of MPNST cells (Fig. 10).

\section{Discussion}

The erbB4 receptor tyrosine kinase has been implicated in the pathogenesis of several human cancers including glioblastomas [36], melanomas [37, 38], medulloblastomas [39], pulmonary adenocarcinomas [40], ovarian carcinomas [41] and esophageal carcinomas [42]. Many of these cancer types also express erbB3, a second NRG1 receptor that is functionally distinct from erbB4. Surprisingly, it has not been clearly established whether the co-

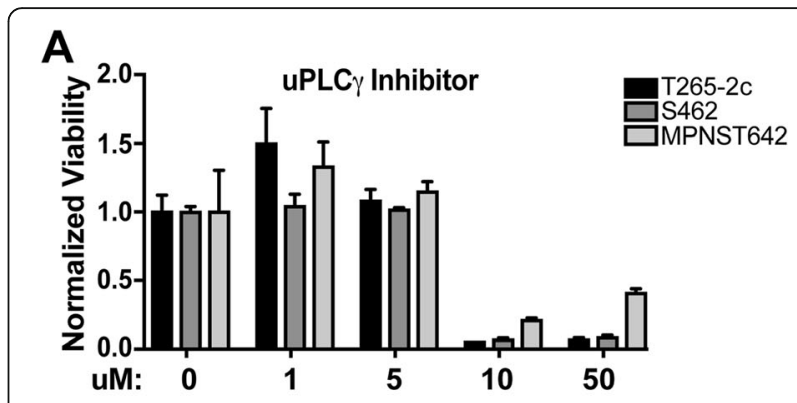

B
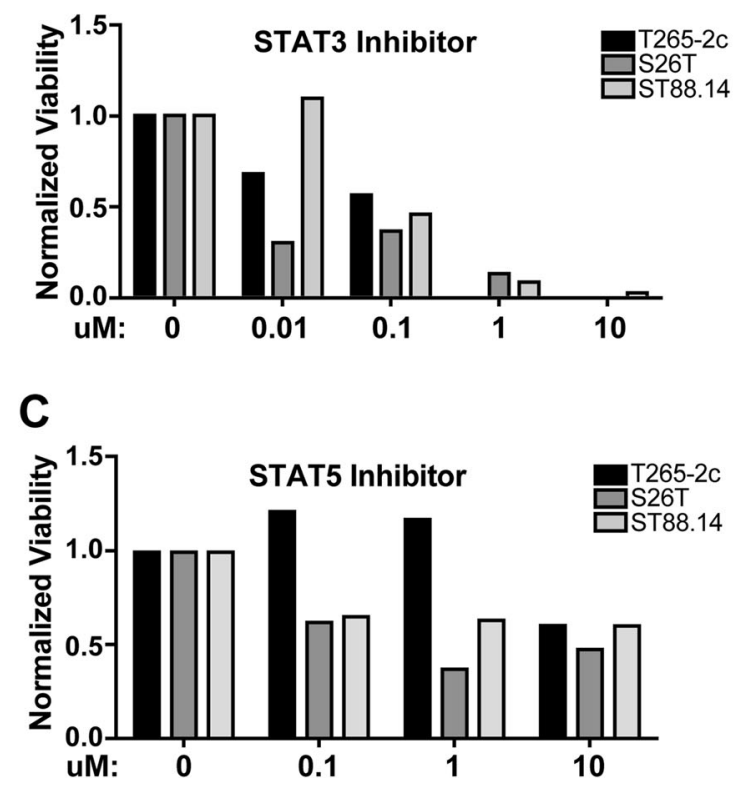

Fig. 8 MPNSTs are sensitive to inhibition of specific erbB4 activated signaling pathways. a-c Cell viability was assessed in three log phase MPNST cell lines in the presence of designated inhibitor. Values represent cell viability after $72 \mathrm{~h}$ of drug treatment normalized to 0 h. After normalization, cell viability for each drug dose was compared to vehicle control. PLC- $\gamma$ inhibition effects cell viability in a dose dependent manner $\mathbf{a}$. STAT3 inhibition significantly affects cell viability (b). STAT5 inhibition modestly affects cell viability (c)

expression of two NRG1 receptors in these neoplasms promotes tumorigenesis and, if they do, whether they do so by increasing receptor numbers (thereby rendering tumor cells more responsive to NRG1 or other erbB ligands) or whether these two receptors instead make distinct, critically important contributions to tumor initiation and progression. The evidence we have obtained using MPNSTs as a model system argues that, at least in this setting, erbB3 and erbB4 promote tumorigenesis by regulating different essential signaling cascades. However, our findings also raise intriguing new questions regarding the mechanisms by which erbB4 drives tumor pathogenesis.

Several lines of evidence reported in this manuscript support the hypothesis that erbB4 promotes MPNST 
A

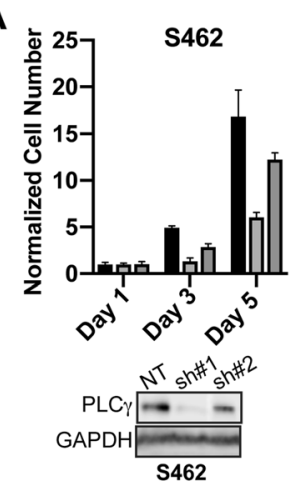

B

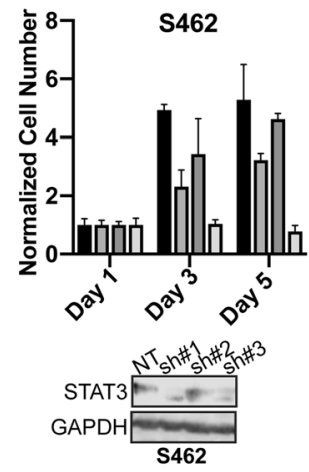

C

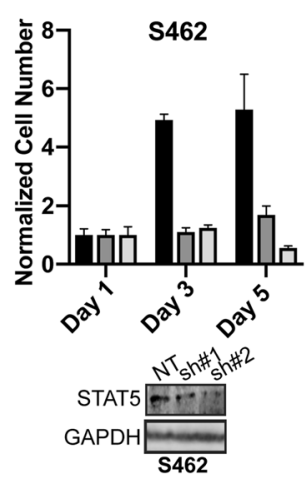

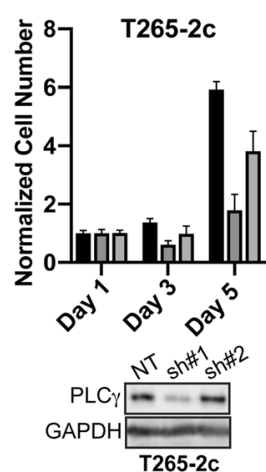
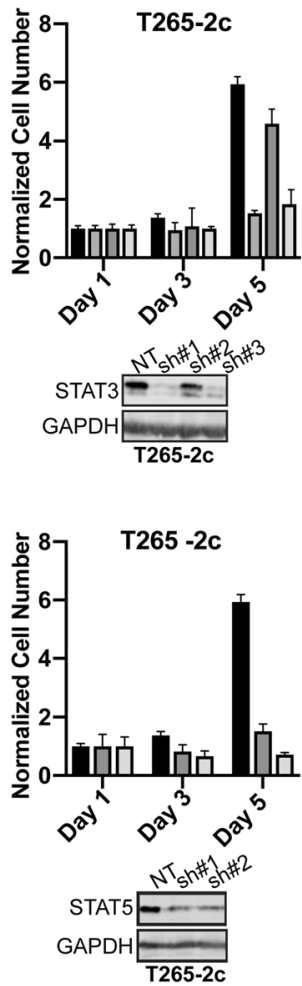
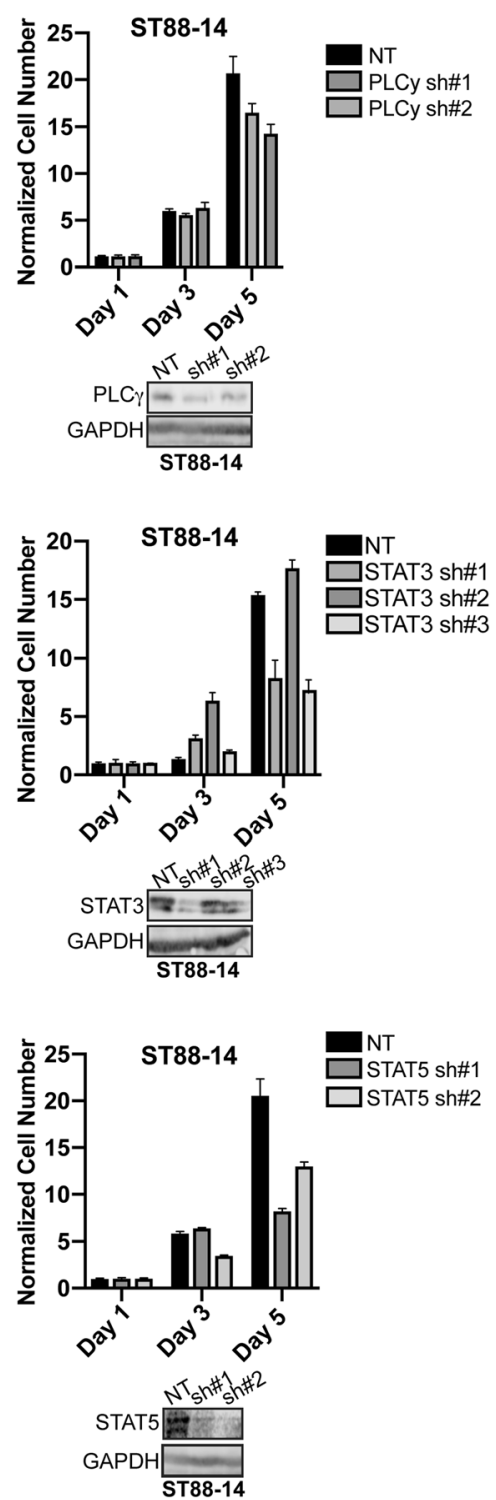

Fig. 9 MPNSTs are sensitive to knockdown of specific erbB4 activated signaling molecules. a-c) Cell proliferation was assessed in three log phase MPNST cell lines in the presence of multiple designated PLCY(a), STAT3 (b), or STAT5 (c) shRNA's or non-targeting controls. Values represent cell number over 5 days of shRNA knockdown normalized to $0 \mathrm{~h}$. PLC- - inhibition effects cell proliferation in a cell-type dependent manner (a). STAT3 inhibition significantly affects cell proliferation (b). STAT5 inhibition significantly affects cell proliferation (c)

pathogenesis. Our immunohistochemical, real time PCR and immunoblotting results demonstrate that multiple erbB4 splice variants, including variants capable of activating PI3K signaling and mediating transcription, are expressed in the overwhelming majority of human and mouse MPNSTs. Ablation of Erbb4 in $\mathrm{P}_{0}$-GGF 33 ; $\operatorname{Trp} 3^{+/-} ;$ErbB $4^{\text {flox/flox }}$ MPNST cells results in altered cellular morphology, increased cell death and reduced proliferation. Further, when allografted in nude mice, Erbb4-null $\mathrm{P}_{0}$-GGF $33 ; \operatorname{Trp53} 3^{+/-}$;Erbb4 $4^{\text {flox/flox }}$ MPNST allografts produce tumors up to $80 \%$ smaller than controls with evidence of decreased mitogenesis, increased cell death and decreased vascular density. Finally, knocking down ERBB4 expression in human MPNST cells has effects on proliferation and survival analogous to those seen in Erbb4-null mouse MPNSTs. We found that loss of erbB4 expression did not reduce the expression of erbB3, the other NRG1 receptor, in these MPNST cells. Further, the Erbb4-null tumor cells are still NRG1responsive, as demonstrated by our phosphorylationspecific antibody array experiments. It is thus apparent that the erbB3 receptors expressed in MPNST cells cannot completely compensate for the loss of erbB4 expression. 


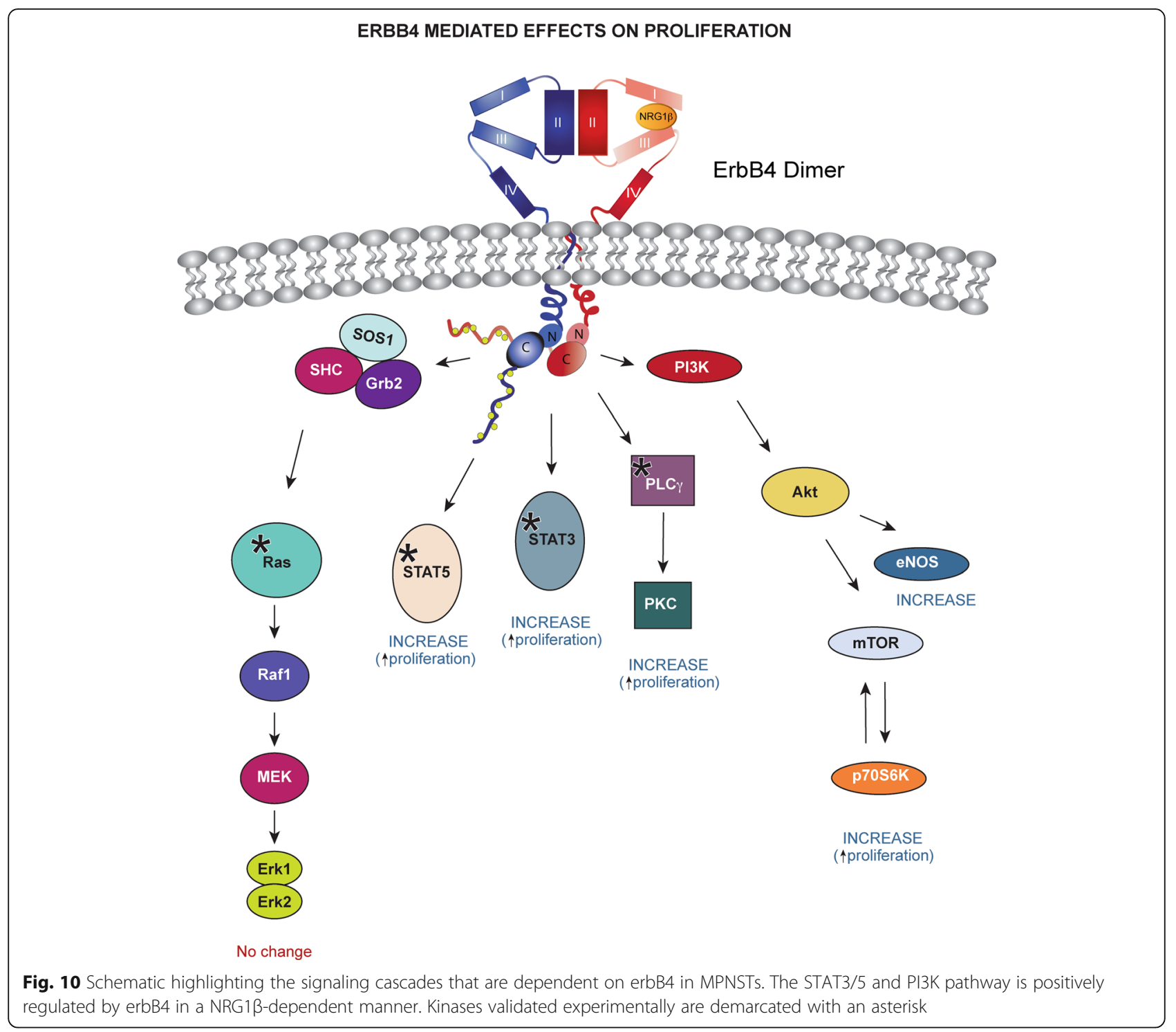

Our findings also indicate that erbB3 and erbB4 mediate distinct effects in MPNST cells. The erbB3 receptors expressed in MPNST cells are clearly functional as the phosphorylation of the Ras downstream effectors Erk-1/2 and JNK-1/2/3 were similarly increased in NRG1 $\beta$-stimulated Erbb4-null cells and unmodified controls. Consequently, the effects we observed following Erbb4 ablation are not due to a loss of NRG1 responsiveness. These changes are also not the result of decreased Ras activation as Ras activation was unaffected by Erbb4 loss. As both erbB3 and erbB4 can activate Ras, this suggests that erbB3 and/ or other erbB receptors compensate for erbB4 loss in MPNST cells to maintain Ras activation. Our demonstration that erbB4 loss results in decreased proliferation and survival thus indicates that erbB4 must promote the proliferation and survival of MPNST cells by regulating other non-Ras dependent signaling cascades.

By comparing kinase phosphorylation in NRG-1 $\beta$ stimulated and unstimulated Erbb4-null and control cells, we identified several candidate kinases that potentially represent the downstream effectors of erbB4mediated proliferation, survival, angiogenesis and, potentially, other effects in MPNSTs. In keeping with our demonstration that MPNST cells express erbB4 splice variants containing the Cyt1 domain, Erbb4-null MPNST cells demonstrated altered phosphorylation of Akt and key Akt targets such as, eNOS, ribosomal p70S6 kinase (S6K) and ribosomal p90S6 kinase (RSK1/ $2 / 3$ ); the phosphorylation of these molecules was decreased in Cre-treated Erbb4 ablated tumor cells, indicating that erbB4 positively regulates the PI3K/Akt/ mTOR signaling cascades in MPNST cells. However, 
erbB-mediated regulation of Akt action in MPNST cells is likely complex. We have found that NRG1 $\beta$, acting through erbB4, reduced the phosphorylation of Akt residue S473 yet we observed an increase in T308 phosphorylation that was at least partially dependent on erbB4. A similar inverse response on Akt has been previously reported in response to ER-stress and is a context dependent mechanism that diversifies Akt signaling [43]. Although the phosphorylation of both of these sites activates Akt, the phosphorylation of these two amino acids is orchestrated by different kinases; S473, which resides in the regulatory domain of Akt, is phosphorylated by mTORC2 and DNA-PK, while T308 which is located in the Akt kinase domain, is a direct target of PDK1. The fact that both S473 and T308 were found to be increased by NRG1 stimulation in the absence of erbB4 suggest that this increase is mediated partially by erbB3. The fact that we see positive regulation of eNOS, a major regulator of angiogenesis, apoptosis, invasion and metastasis, strongly suggests that PDK1-Akt (T308) promotes MPNST growth downstream of erbB4 and thus may be a useful therapeutic target. However, regulation of the PI3K pathway is often further complicated by the expression of multiple PDK1 isoforms that have opposing effects on mTORC1 activity. We would also point out that erbB3, which is also activated by NRG1, contains multiple docking sites for the regulatory p85 subunit of PI3 kinase and thus also likely plays an important role in the regulation of the PI3K/Akt signaling cascade in MPNST cells. It will be of great interest to determine how erbB3 and erbB4 inputs into the PI3K/Akt signaling pathway interact in MPNST cells.

We have also found that erbB4 promotes the phosphorylation of PLC- $\gamma$, a protein that promotes the pathogenesis of many tumor types. Inhibition of PLC- $\gamma$ action in MPNST cells reduced the number of viable cells, indicating that PLC- $\gamma$ has a similar role in MPNSTs. In addition, we discovered that erbB4 regulates the phosphorylation of two molecules-with-no-lysine kinase 1 (WNK1), a kinase that is phosphorylated at Thr60 by Akt [44], and heat shock protein 60 (HSP60)-that promote tumorigenesis in other cancer types. In glioma cells, WNK1 associates with multiple ion transporters and contributes to migration by modulating volumetric changes [45]. This action is consistent with our observation that Erbb4 ablation alters the morphology of MPNST cells. However, in HeLa cells, WNK1 associates with mitotic spindles and promotes mitosis and abscission; loss of this kinase results in aberrant mitotic spindle formation, defective cell division and cell death [46]. In contrast to the findings in HeLa cells, we found that WNK1 knockdown did not impair the proliferation and survival of MPNST cells. Further, we commonly observed multinucleated cells in control tumors but not
Erbb4-null tumors; this is the opposite of what we would expect based on the earlier findings in HeLa cells. These findings thus suggest that WNK1 functions in MPNST cells differ from those observed in other tumor types. Heat shock proteins are upregulated in response to cellular stress and chaperone protein folding. However, heat shock protein expression in tumors is not strictly linked to stress [47]; these proteins also facilitate evasion of apoptosis [48] and help tumor cells escape or inhibit immune system surveillance. These latter HSP60 actions raise the question of whether erbB4 promotes MPNST pathogenesis via analogous mechanisms.

In MPNSTs, we found that erbB4 promotes nuclear signaling by phosphorylating STAT3 and STAT5, two downstream targets of the mTOR and Jak/Stat signaling pathways. Our demonstration that pharmacologic inhibition of STAT3 and STAT5 action decreases the number of viable cells in vitro indicates that phosphorylation of STAT3 and STAT5 is essential for MPNST proliferation and/or survival. This suggestion is consistent with previous observations indicating that elevated expression of both of these STAT proteins is seen in numerous cancers, where their phosphorylation results in enhanced expression of cell cycle progression (e.g., cyclin D1 [49, 50]) and survival (e.g., Bcl-xL and $\mathrm{Bcl}-2$ [51-53]) genes. The absence of STAT5 activation that we observed in Erbb4-null cells is consistent with earlier reports that erbB4 activates STAT5, leading to its transport to the nucleus. However, the changes in STAT3 activity were unexpected, as STAT3 is activated by erbB2 or EGFR in other cell types, not erbB4. It is unlikely that erbB2 drives STAT3 phosphorylation in these tumors as Erbb4-null MPNST cells remain NRG-1-responsive and express erbB3, a receptor that dimerizes with erbB2 to form an active NRG1 signaling complex. These observations thus raise the interesting possibility that erbB4 regulates STAT3 phosphorylation in MPNST cells via a previously unknown mechanism.

Interestingly, although some signaling cascades were activated in MPNST cells by NRG1 $\beta$ stimulation, others such as p70S6 kinase, STAT3, WNK1 and HSP60 displayed equivalent levels of phosphorylation in the presence and absence of exogenous NRG1 $\beta$. Nonetheless, Erbb4 ablation reduced the phosphorylation of these proteins, indicating that erbB4 regulated their phosphorylation. One potential explanation for this conundrum is that the basal level of stimulation provided by tumor cell-derived NRG1 [16] is sufficient to maximally drive the phosphorylation of these proteins. An alternative explanation, however, reflects the fact that erbB4 is not just a NRG1 receptor; it also responds to NRG2, NRG3, NRG4, heparin-binding EGF, betacellulin and epiregulin. We have previously shown that heparin-binding EGF, betacellulin and epiregulin expression is much lower in 
human MPNST cells than non-neoplastic Schwann cells [27], making it unlikely that these factors play major roles in promoting erbB4 activation. To the best of our knowledge, however, NRG2, NRG3 and NRG4 action has not been carefully examined in MPNSTs. Consequently, we cannot rule out the possibility that one or more of these growth factors contributes to the baseline activation of erbB4 in MPNST cells and drives the phosphorylation of some erbB4 target molecules.

\section{Conclusions}

In summary, multiple erbB4 splice variants are commonly expressed in MPNSTs. Acting in a cell-autonomous manner, these erbB4 variants promote the proliferation and survival of tumor cells. ErbB4 receptors expressed by MPNST cells also indirectly promote angiogenesis in MPNSTs. Despite our anticipation that erbB4 would drive Ras activation, we found that erbB4 instead promotes MPNST pathogenesis via Ras-independent effects; these signaling events include alterations in the PI3K/Akt/ mTOR and PLC- $\gamma$ signaling cascades, activation of transcription via STAT proteins, and the phosphorylation of other molecules with oncogenic potential, such as HSP60. Our findings thus identify erbB4 and key erbB4dependent signaling pathways as potentially important chemotherapeutic targets in MPNSTs. Future studies will be needed to further investigate the role of the other erbB4 targets that we have identified in MPNST pathogenesis. It will also be of great interest to establish the relative contributions that canonical membrane-based erbB4 signaling and transcriptional signaling by the erbB4 intracellular domain make to the development of these aggressive spindle cell neoplasms.

\section{Additional file}

Additional file 1: Figure S1. ErbB4 lysates are sensitive to denaturing detergents. Table S1. Patient demographics for immunostained MPNSTs. Figure S2 Real-time PCR analyses of erbB4 splice variants and mouse MPNST erbB4 expression. Table S2. MPNST locations in $\mathrm{P}_{0}-\mathrm{GGF} \beta 3 ;$ Trp53 ${ }^{+/-}$;Erbb4 $4^{\text {flox/flox }}$ mice. Figure S3. Validation of Erbb4 ablation and effects on expression of other erbB receptors. Figure S4. Kinase array blots for NRG1 $\beta$ and unstimulated control and Erbb4-null MPNST cells. Figure S5. Downregulation of WNK1 expression did not affect cell viability. (ZIP $7528 \mathrm{~kb}$ )

\section{Abbreviations}

MPNST: Malignant peripheral nerve sheath tumor; NF1: Neurofibromatosis type 1; NRG: Neuregulin; PI3K: Phosphatidylinositol-3 kinase; PLCY: Phospholipase C Y; RTK: Receptor tyrosine kinase; WNK1: With no lysines 1

\section{Acknowledgements}

We thank the Medical University of South Carolina Hollings Cancer Center Biorepository \& Tissue Analysis Shared Resource (P30 CA138313), the Genomics/shRNA Shared Resource and the Center for Genomic Medicine for providing crucial specimens, reagents and sequencing, respectively.

\section{Authors' contributions}

JFL, RCW, KAR and SLC conceived and designed the experiments and provided oversight of the research project and grant funding. SNB, JFL, LB and SJW performed the experiments. SNB, JFL, and SLC prepared the manuscript. All authors have read and approved the final manuscript.

\section{Funding}

This work was supported by grants from the National Institute of Neurological Diseases and Stroke (R01 NS048353 to SLC, F31 NS081824 to SNB), the National Cancer Institute (R01 CA122804 to SLC and R01 CA134773 to KAR), the Department of Defense (X81XWH-09-1-0086, W81XWH-12-1-0164 and W81XWH-15-1-0193 to SLC and W81XWH-14-1-0073 to KAR) and The Children's Tumor Foundation (2014-04-001 and 2015-05-007 to SLC). Supported in part by the Genomics Shared Resource, Hollings Cancer Center, Medical University of South Carolina.

\section{Availability of data and materials}

All data generated or analyzed during this study are included in this published article and supplementary information files.

\section{Ethics approval and consent to participate}

The human studies presented in this manuscript were reviewed and approved by the University of Alabama at Birmingham and the Medical University of South Carolina Institutional Review Boards for Human Use and were performed in accordance with the ethical standards of the 1964 Helsinki Declaration and its later amendments. The University of Alabama at Birmingham and the Medical University of South Carolina Institutional Animal Care and Use Committees approved all animal experiments.

\section{Consent for publication}

Not applicable.

\section{Competing interests}

The authors declare that they have no competing interests.

\section{Author details}

'Department of Pathology (SNB, KAR) and the Medical Scientist Training Program (SNB), University of Alabama at Birmingham, Birmingham, AL 35294-0017, USA. ²Department of Pathology and Laboratory Medicine (JFL, LB, RCW, SJW, SLC), Medical University of South Carolina, 171 Ashley Avenue, MSC 908, Charleston, SC 29425-9080, USA. ${ }^{3}$ Present address: Department of Pediatrics at The Children's Hospital of Philadelphia, Philadelphia, PA, USA.

${ }^{4}$ Present address: Department of Pathology and Cell Biology, Vagelos College of Physicians and Surgeons, Columbia University, New York City, NY, USA

Received: 12 March 2019 Accepted: 2 July 2019

Published online: 10 July 2019

\section{References}

1. Carroll SL. Molecular mechanisms promoting the pathogenesis of Schwann cell neoplasms. Acta Neuropathol. 2012;123:321-48.

2. Rasmussen SA, Yang Q, Friedman JM. Mortality in neurofibromatosis 1: an analysis using U.S. death certificates. Am J Hum Genet. 2001;68:1110-8.

3. LaFemina J, Qin LX, Moraco NH, Antonescu CR, Fields RC, Crago AM, Brennan MF, Singer S. Oncologic outcomes of sporadic, neurofibromatosisassociated, and radiation-induced malignant peripheral nerve sheath tumors. Ann Surg Oncol. 2013;20:66-72.

4. Stucky CC, Johnson KN, Gray RJ, Pockaj BA, Ocal IT, Rose PS, Wasif N. Malignant peripheral nerve sheath tumors (MPNST): the Mayo Clinic experience. Ann Surg Oncol. 2012;19:878-85.

5. Kolberg M, Holand M, Agesen TH, Brekke HR, Liestol K, Hall KS, Mertens F, Picci P, Smeland S, Lothe RA. Survival meta-analyses for $>1800$ malignant peripheral nerve sheath tumor patients with and without neurofibromatosis type 1. Neuro-Oncology. 2013;15:135-47.

6. Porter DE, Prasad V, Foster L, Dall GF, Birch R, Grimer RJ. Survival in malignant peripheral nerve sheath Tumours: a comparison between sporadic and Neurofibromatosis type 1-associated Tumours. Sarcoma. 2009; 2009:756395.

7. Watson $\mathrm{KL}$, Al Sannaa GA, Kivlin CM, Ingram DR, Landers SM, Roland CL, Cormier JN, Hunt KK, Feig BW, Ashleigh Guadagnolo B, et al. Patterns of recurrence and survival in sporadic, neurofibromatosis type 1-associated, and radiation-associated malignant peripheral nerve sheath tumors. J Neurosurg. 2017;126:319-29. 
8. Zou C, Smith KD, Liu J, Lahat G, Myers S, Wang WL, Zhang W, McCutcheon IE, Slopis JM, Lazar AJ, et al. Clinical, pathological, and molecular variables predictive of malignant peripheral nerve sheath tumor outcome. Ann Surg. 2009:249:1014-22

9. Ducatman BS, Scheithauer BW, Piepgras DG, Reiman HM, Ilstrup DM Malignant peripheral nerve sheath tumors. A clinicopathologic study of 120 cases. Cancer. 1986;57:2006-21.

10. Anghileri $M$, Miceli R, Fiore $M$, Mariani $L$, Ferrari A, Mussi $C$, Lozza L, Collini $P$, Olmi P, Casali PG, et al. Malignant peripheral nerve sheath tumors: prognostic factors and survival in a series of patients treated at a single institution. Cancer. 2006;107:1065-74.

11. Fan Q, Yang J, Wang G. Clinical and molecular prognostic predictors of malignant peripheral nerve sheath tumor. Clin Transl Oncol. 2014;16:191-9.

12. Valentin T, Le Cesne A, Ray-Coquard I, Italiano A, Decanter G, Bompas E, Isambert N, Thariat J, Linassier C, Bertucci F, et al. Management and prognosis of malignant peripheral nerve sheath tumors: the experience of the French sarcoma group (GSF-GETO). Eur J Cancer. 2016;56:77-84.

13. Lee W, Teckie S, Wiesner T, Ran L, Prieto Granada CN, Lin M, Zhu S, Cao Z, Liang Y, Sboner A, et al. PRC2 is recurrently inactivated through EED or SUZ12 loss in malignant peripheral nerve sheath tumors. Nat Genet. 2014; 46:1227-32.

14. Zhang M, Wang Y, Jones S, Sausen M, McMahon K, Sharma R, Wang Q, Belzberg AJ, Chaichana K, Gallia GL, et al. Somatic mutations of SUZ12 in malignant peripheral nerve sheath tumors. Nat Genet. 2014;46:1170-2.

15. Brossier NM, Prechtl AM, Longo JF, Barnes S, Wilson LS, Byer SJ, Brosius SN, Carroll SL. Classic Ras proteins promote proliferation and survival via distinct Phosphoproteome alterations in Neurofibromin-null malignant peripheral nerve sheath tumor cells. J Neuropathol Exp Neurol. 2015;74:568-86.

16. Stonecypher MS, Byer SJ, Grizzle WE, Carroll SL. Activation of the neuregulin-1/ErbB signaling pathway promotes the proliferation of neoplastic Schwann cells in human malignant peripheral nerve sheath tumors. Oncogene. 2005:24:5589-605.

17. Eckert JM, Byer SJ, Clodfelder-Miller BJ, Carroll SL. Neuregulin-1 beta and neuregulin-1 alpha differentially affect the migration and invasion of malignant peripheral nerve sheath tumor cells. Glia. 2009;57:1501-20.

18. Kazmi SJ, Byer SJ, Eckert JM, Turk AN, Huijbregts RP, Brossier NM, Grizzle WE, Mikhail FM, Roth KA, Carroll SL. Transgenic mice overexpressing neuregulin1 model neurofibroma-malignant peripheral nerve sheath tumor progression and implicate specific chromosomal copy number variations in tumorigenesis. Am J Pathol. 2013;182:646-67.

19. Huijbregts RP, Roth KA, Schmidt RE, Carroll SL. Hypertrophic neuropathies and malignant peripheral nerve sheath tumors in transgenic mice overexpressing glial growth factor beta3 in myelinating Schwann cells. J Neurosci. 2003;23:7269-80

20. Brosius SN, Turk AN, Byer SJ, Brossier NM, Kohli L, Whitmire A, Mikhail FM, Roth KA, Carroll SL. Neuregulin-1 overexpression and Trp53 haploinsufficiency cooperatively promote de novo malignant peripheral nerve sheath tumor pathogenesis. Acta Neuropathol. 2014;127:573-91.

21. Carraway KL 3rd, Cantley LC. A neu acquaintance for erbB3 and erbB4: a role for receptor heterodimerization in growth signaling. Cell. 1994;78:5-8.

22. Sawyer C, Hiles I, Page M, Crompton M, Dean C. Two erbB-4 transcripts are expressed in normal breast and in most breast cancers. Oncogene. 1998;17:919-24.

23. Vecchi M, Carpenter G. Constitutive proteolysis of the ErbB-4 receptor tyrosine kinase by a unique, sequential mechanism. J Cell Biol. 1997;139: 995-1003.

24. Zhou W, Carpenter G. Heregulin-dependent trafficking and cleavage of ErbB-4. J Biol Chem. 2000;275:34737-43.

25. Sardi SP, Murtie J, Koirala S, Patten BA, Corfas G. Presenilin-dependent ErbB4 nuclear signaling regulates the timing of astrogenesis in the developing brain. Cell. 2006;127:185-97.

26. Byer SJ, Eckert JM, Brossier NM, Clodfelder-Miller BJ, Turk AN, Carroll AJ, Kappes JC, Zinn KR, Prasain JK, Carroll SL. Tamoxifen inhibits malignant peripheral nerve sheath tumor growth in an estrogen receptorindependent manner. Neuro-Oncology. 2011;13:28-41.

27. Byer SJ, Brossier NM, Peavler LT, Eckert JM, Watkins S, Roth KA, Carroll SL. Malignant peripheral nerve sheath tumor invasion requires aberrantly expressed EGF receptors and is variably enhanced by multiple EGF family ligands. J Neuropathol Exp Neurol. 2013;72:219-33.

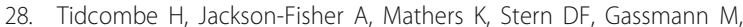
Golding JP. Neural and mammary gland defects in ErbB4 knockout mice genetically rescued from embryonic lethality. Proc Natl Acad Sci U S A. 2003;100:8281-6.

29. Long W, Wagner KU, Lloyd KC, Binart N, Shillingford JM, Hennighausen L, Jones FE. Impaired differentiation and lactational failure of Erbb4-deficient mammary glands identify ERBB4 as an obligate mediator of STAT5. Development. 2003;130:5257-68.

30. Golub MS, Germann SL, Lloyd KC. Behavioral characteristics of a nervous system-specific erbB4 knock-out mouse. Behav Brain Res. 2004; 153:159-70.

31. Jackson-Fisher AJ, Bellinger G, Shum E, Duong JK, Perkins AS, Gassmann M, Muller W, Kent Lloyd KC, Stern DF. Formation of Neu/ErbB2-induced mammary tumors is unaffected by loss of ErbB4. Oncogene. 2006;25:5664-72.

32. Turk AN, Byer SJ, Zinn KR, Carroll SL. Orthotopic xenografting of human luciferase-tagged malignant peripheral nerve sheath tumor cells for in vivo testing of candidate therapeutic agents. J Vis Exp. 2011. p. 49. https://doi. org/10.3791/2558

33. Gassmann M, Casagranda F, Orioli D, Simon H, Lai C, Klein R, Lemke G. Aberrant neural and cardiac development in mice lacking the ErbB4 neuregulin receptor. Nature. 1995;378:390-4.

34. Tansey MG, Chu GC, Merlie JP. ARIA/HRG regulates AChR epsilon subunit gene expression at the neuromuscular synapse via activation of phosphatidylinositol 3-kinase and Ras/MAPK pathway. J Cell Biol. 1996;134: 465-76.

35. Mi H, Muruganujan A, Ebert D, Huang X, Thomas PD. PANTHER version 14: more genomes, a new PANTHER GO-slim and improvements in enrichment analysis tools. Nucleic Acids Res. 2019;47:D419-26.

36. Carrasco-Garcia E, Saceda M, Grasso S, Rocamora-Reverte L, Conde M, Gomez-Martinez A, Garcia-Morales P, Ferragut JA, Martinez-Lacaci I. Small tyrosine kinase inhibitors interrupt EGFR signaling by interacting with erbB3 and erbB4 in glioblastoma cell lines. Exp Cell Res. 2011;317:1476-89.

37. Easty DJ, Gray SG, O'Byrne KJ, O'Donnell D, Bennett DC. Receptor tyrosine kinases and their activation in melanoma. Pigment Cell Melanoma Res. 2011;24:446-61.

38. Xia J, Jia P, Hutchinson KE, Dahlman KB, Johnson D, Sosman J, Pao W, Zhao Z. A meta-analysis of somatic mutations from next generation sequencing of 241 melanomas: a road map for the study of genes with potential clinical relevance. Mol Cancer Ther. 2014;13:1918-28.

39. Gilbertson R, Hernan R, Pietsch T, Pinto L, Scotting P, Allibone R, Ellison D, Perry $R$, Pearson A, Lunec J. Novel ERBB4 juxtamembrane splice variants are frequently expressed in childhood medulloblastoma. Genes Chromosomes Cancer. 2001;31:288-94.

40. Nakaoku T, Tsuta K, Ichikawa H, Shiraishi K, Sakamoto H, Enari M, Furuta K, Shimada Y, Ogiwara H, Watanabe S, et al. Druggable oncogene fusions in invasive mucinous lung adenocarcinoma. Clin Cancer Res. 2014;20:3087-93.

41. Paatero I, Lassus H, Junttila TT, Kaskinen M, Butzow R, Elenius K. CYT-1 isoform of ErbB4 is an independent prognostic factor in serous ovarian cancer and selectively promotes ovarian cancer cell growth in vitro. Gynecol Oncol. 2013;129:179-87.

42. Silva SD, Alaoui-Jamali MA, Hier M, Soares FA, Graner E, Kowalski LP. Cooverexpression of ERBB1 and ERBB4 receptors predicts poor clinical outcome in pN+ oral squamous cell carcinoma with extranodal spread. Clin Exp Metastasis. 2014;31:307-16.

43. Szymonowicz K, Oeck S, Malewicz NM, Jendrossek V. New insights into protein kinase B/Akt signaling: role of localized Akt activation and compartment-specific target proteins for the cellular radiation response. Cancers (Basel). 2018. p. 10. https://doi.org/10.3390/cancers10030078.

44. Vitari AC, Deak M, Collins BJ, Morrice N, Prescott AR, Phelan A, Humphreys S, Alessi DR. WNK1, the kinase mutated in an inherited high-blood-pressure syndrome, is a novel PKB (protein kinase B)/Akt substrate. Biochem J. 2004; 378:257-68.

45. Zhu W, Begum G, Pointer K, Clark PA, Yang SS, Lin SH, Kahle KT, Kuo JS, Sun D. WNK1-OSR1 kinase-mediated phospho-activation of $\mathrm{Na}+-\mathrm{K}+-2 \mathrm{Cl}$ cotransporter facilitates glioma migration. Mol Cancer. 2014;13:31.

46. Tu SW, Bugde A, Luby-Phelps K, Cobb MH. WNK1 is required for mitosis and abscission. Proc Natl Acad Sci U S A. 2011;108:1385-90.

47. Rappa F, Unti E, Baiamonte P, Cappello F, Scibetta N. Different immunohistochemical levels of $\mathrm{Hsp60}$ and $\mathrm{Hsp70}$ in a subset of brain tumors and putative role of Hsp60 in neuroepithelial tumorigenesis. Eur 」 Histochem. 2013;57:e20.

48. Campanella C, Bucchieri F, Ardizzone NM, Marino Gammazza A, Montalbano A, Ribbene A, Di Felice V, Bellafiore M, David S, Rappa F, et al. Upon 
oxidative stress, the antiapoptotic Hsp60/procaspase-3 complex persists in mucoepidermoid carcinoma cells. Eur J Histochem. 2008;52:221-8.

49. Leslie K, Lang C, Devgan G, Azare J, Berishaj M, Gerald W, Kim YB, Paz K, Darnell JE, Albanese C, et al. Cyclin D1 is transcriptionally regulated by and required for transformation by activated signal transducer and activator of transcription 3. Cancer Res. 2006;66:2544-52.

50. Kong J, Kong F, Gao J, Zhang Q, Dong S, Gu F, Ke S, Pan B, Shen Q, Sun H, et al. YC-1 enhances the anti-tumor activity of sorafenib through inhibition of signal transducer and activator of transcription 3 (STAT3) in hepatocellular carcinoma. Mol Cancer. 2014;13:7.

51. Gu L, Vogiatzi P, Puhr M, Dagvadorj A, Lutz J, Ryder A, Addya S, Fortina P, Cooper C, Leiby B, et al. Stat5 promotes metastatic behavior of human prostate cancer cells in vitro and in vivo. Endocr Relat Cancer. 2010;17:481-93.

52. Gu L, Dagvadorj A, Lutz J, Leiby B, Bonuccelli G, Lisanti MP, Addya S, Fortina P, Dasgupta A, Hyslop T, et al. Transcription factor Stat3 stimulates metastatic behavior of human prostate cancer cells in vivo, whereas Stat5b has a preferential role in the promotion of prostate cancer cell viability and tumor growth. Am J Pathol. 2010;176:1959-72.

53. Sanchez-Ceja SG, Reyes-Maldonado E, Vazquez-Manriquez ME, Lopez-Luna $\mathrm{JJ}$, Belmont A, Gutierrez-Castellanos S. Differential expression of STAT5 and $\mathrm{BCl}-\mathrm{xL}$, and high expression of Neu and STAT3 in non-small-cell lung carcinoma. Lung Cancer. 2006;54:163-8.

\section{Publisher's Note}

Springer Nature remains neutral with regard to jurisdictional claims in published maps and institutional affiliations.

Ready to submit your research? Choose BMC and benefit from:

- fast, convenient online submission

- thorough peer review by experienced researchers in your field

- rapid publication on acceptance

- support for research data, including large and complex data types

- gold Open Access which fosters wider collaboration and increased citations

- maximum visibility for your research: over $100 \mathrm{M}$ website views per year

At $\mathrm{BMC}$, research is always in progress.

Learn more biomedcentral.com/submissions 